\title{
Classical Trajectories and RRKM Modeling of Collisional Excitation and Dissociation of Benzylammonium and tert-Butyl Benzylammonium Ions in a Quadrupole-Hexapole-Quadrupole Tandem Mass Spectrometer
}

\author{
Vadim D. Knyazev ${ }^{\mathrm{a}, \mathrm{b}}$ and Stephen E. Stein ${ }^{\mathrm{a}}$ \\ a National Institute of Standards and Technology, Physical and Chemical Properties Division, Gaithersburg, \\ Maryland, USA \\ ${ }^{b}$ Research Center for Chemical Kinetics, Department of Chemistry, The Catholic University of America, \\ Washington, District of Columbia, USA
}

Collision-induced dissociation of the benzylammonium and the 4-tert-butyl benzylammonium ions was studied experimentally in an electrospray ionization quadrupole-hexapole-quadrupole tandem mass spectrometer. Ion fragmentation efficiencies were determined as functions of the kinetic energy of ions and the collider gas (argon) pressure. A theoretical Monte Carlo model of ion collisional excitation, scattering, and decomposition was developed. The model includes simulation of the trajectories of the parent and the product ions flight through the hexapole collision cell, quasiclassical trajectory modeling of collisional activation and scattering of ions, and Rice-Ramsperger-Kassel-Marcus (RRKM) modeling of the parent ion decomposition. The results of modeling demonstrate a general agreement between calculations and experiment. Calculated values of ion fragmentation efficiency are sensitive to initial vibrational excitation of ions, scattering of product ions from the collision cell, and distribution of initial ion velocities orthogonal to the axis of the collision cell. Three critical parameters of the model were adjusted to reproduce the experimental data on the dissociation of the benzylammonium ion: reaction enthalpy and initial internal and translational temperatures of the ions. Subsequent application of the model to decomposition of the $t$-butyl benzylammonium ion required adjustment of the internal ion temperature only. Energy distribution functions obtained in modeling depend on the average numbers of collisions between the ion and the atoms of the collider gas and, in general, have non-Boltzmann shapes. (J Am Soc Mass Spectrom 2010, 21, 425-439) () 2010 American Society for Mass Spectrometry

$\mathrm{F}$ ragmentation of gaseous ions has long been an important source of information on the properties of these ions and the corresponding parent species. Studies of collision-induced dissociation (CID) mass spectra of many types of ions provide important information on their structure, thermochemistry, and other properties; recently, the main focus of such studies shifted to the analysis of large biomolecules, such as proteins and peptides (e.g., [1-11].

As a result of many studies, the many features of collisional ion dissociation have been elucidated, including those of fragmentation of the ions of large biomolecules (e.g., [9, 12-17] and references therein). However, the factors that determine absolute and relative abundances of possible fragments are not well understood, certainly not to the point that would enable

Address reprint requests to Professor V. D. Knyazev, Research Center for Chemical Kinetics, Department of Chemistry, The Catholic University of America, Washington, DC 20064, USA). E-mail: knyazev@cua.edu quantitative prediction of CID mass spectra. It is generally understood that the successful modeling of collisional ion dissociation would require correct quantitative description of three factors: (1) the chemical mechanism of fragmentation (i.e., the sequence of intramolecular rearrangements and decomposition and the potential energy surfaces of these processes), (2) rovibrational excitation of the parent ion as a result of collisions with the inert collider gas, and (3) kinetics of the dissociation of ions in competition with deactivating collisions and removal of ions (via scattering or detection) from the collision cell of the mass spectrometer. A number of earlier studies concentrated on modeling one or two of these factors; reviews can be found in $[9,18]$. Among these three factors, the collisional excitation of ions is probably the one least well understood. Usually, the results of modeling of experimental ion fragmentation data are presented in a form of effective temperatures, with an implicit assumption that single or multiple collisions of ions with the inert collider gas yield 
energy distributions that are similar to the Boltzmann distribution in their shapes, although evidence of nonBoltzmann behavior exists in the literature (e.g., [10, 19-22]. However, the goal of achieving the ability to predict these energy distributions is far from being realized. The most important characteristic of collisional energy-transfer needed to be understood is the percollision activation function, $P\left(E, E^{\prime}, E_{\mathrm{COLL}}\right)$, the probability of energy transfer from energy $E^{\prime}$ to energy $E$ upon a collision with a collider gas atom or molecule with the relative kinetic energy $E_{\mathrm{COLL}}$.

In a number of earlier works, experimental results of CID experiments were used to derive various features of energy distributions resulting from gas-phase collisional activation of ions [23-30]. In a series of studies ([31-33] and references therein), the "survival yield" method was used to evaluate the shapes of energy distributions. In this method, the survival yield (fraction of nonfragmented ions) was studied as a function of the ion fragmentation energy barrier for a series of similar ions with different substituents (such as benzylpyridinium salts). The resultant dependences were analyzed using Rice-Ramsperger-Kassel-Marcus (RRKM) modeling to derive the energy distribution functions. Vekey and coworkers performed a series of RRKM and Master Equation modeling studies of collisional energytransfer and CID, with the "survival yield" and other types of experiments supplying empirical data (e.g., references [30, 32-37]. Laskin and coworkers performed a series of studies directed at characterization of collisional energy-transfer in multicollisional CID MS and analyzing fragmentation energetics of large ions, including peptide ions [18, 19, 38-42]. These authors used RRKM/Master Equation modeling of CID in FT-ICR mass spectrometer and proposed an analytical form of the activation function [19]. An informative review of studies directed at determining energy distributions resulting from collisional ion activation is given in [18]. In a series of studies, Armentrout and coworkers investigated collision-induced dissociation of small polyatomic ions under the conditions of low pressures, where most ions experience only single collisions with the inert collider gas (e.g., references [11, 20, 43, 44]. These authors concentrated on determination of reaction threshold energies, and performed RRKM modeling of the experimental data using a functional form of the internal energy distribution derived from a theoretical analysis of an empirical model of the collisional energy dependences of the effective reaction cross sections $[45,46]$.

A significant effort towards understanding the characteristics of per-collision activation functions was performed by Meroueh and Hase [21, 22]. These authors studied energy-transfer in activation of peptide ions by collisions with noble gas atoms (mostly argon) using classical trajectory calculations. In these theoretical studies, dependences of energy-transfer on peptide size and conformation, relative kinetic energy of colliders, peptide temperature, intermolecular potential, and col- lider mass were studied. Rather broad $P\left(E, E^{\prime}, E_{\mathrm{COLL}}\right)$ distribution functions were obtained, with considerable contributions at both small and large $\Delta E=E^{\prime}-E$ values. Average energy-transfer efficiency was shown to be large, in the range of $\sim 40-80 \%$. Energy-transfer was found to moderately increase with the size of the peptide and to be somewhat more efficient for folded structures as compared to extended conformations. It was demonstrated that the energy-transfer efficiency is sensitive to the repulsive part of the intermolecular potential and to the collider mass: heavy atoms such as $\mathrm{Kr}$ and $\mathrm{Xe}$ are more efficient activators than a light collider like He. Meroueh and Hase also analyzed collisional rotational activation; the results demonstrated that between $1 \%$ and $8 \%$ of the relative kinetic energy of colliders can be deposited into degrees of freedom of peptide corresponding to its overall rotations. Efficiency of rotational excitation decreased with the increasing relative kinetic energy. In a recent work, Martinez-Nunez et al. [47] extended the method of Meroueh and Hase by including a Morse function term in the force field describing the potential energy surface of the ion and thus enabling modeling of ion dissociation. These authors applied the method to modeling $\mathrm{CID}$ of $\mathrm{Cr}(\mathrm{CO})_{6}^{+}$in collisions with Xe. The results of modeling were in general agreement with the experimental data of Muntean and Armentrout [20].

In the current study, we performed a first-principles modeling of collisional activation and dissociation of two small ions (benzylammonium and 4-tert-butyl benzylammonium) in a quadrupole-hexapole-quadrupole tandem CID mass spectrometer.

$$
\begin{aligned}
& \mathrm{C}_{6} \mathrm{H}_{5} \mathrm{CH}_{2} \mathrm{NH}_{3}^{+} \rightarrow \mathrm{C}_{6} \mathrm{H}_{5} \mathrm{CH}_{2}^{+}+\mathrm{NH}_{3} \\
& \mathrm{C}\left(\mathrm{CH}_{3}\right)_{3} \mathrm{C}_{6} \mathrm{H}_{4} \mathrm{CH}_{2} \mathrm{NH}_{3}^{+} \rightarrow \mathrm{C}\left(\mathrm{CH}_{3}\right)_{3} \mathrm{C}_{6} \mathrm{H}_{4} \mathrm{CH}_{2}^{+}+\mathrm{NH}_{3}
\end{aligned}
$$

The potential energy surfaces of the reactions were studied using quantum chemical methods. Collisional activation was described by performing quasiclassical trajectory calculations using the method similar to that of Meroueh and Hase. Kinetics of ion dissociation was modeled using the RRKM method. The trajectories of ion flight through the collision cell of mass spectrometer were modeled using classical mechanics in a Monte Carlo approach; processes of collisional activation, deactivation, energy-dependent dissociation, and scattering out of the cell were included explicitly.

The modeling results were compared with the experimental data on ion fragmentation obtained in the current work.

\section{Experimental}

Ion fragmentation was studied by electrospray ionization mass spectrometry using a Micromass Quattro Micro instrument [48]. The solution was injected with a syringe at a flow rate of $10 \mathrm{~mL} / \mathrm{min}$ and the positive ion spectrum was recorded in a "continuum" mode from 
$m / z 20$ to 200 . The cone voltages were selected to optimize the parent ion signal (15 and $20 \mathrm{~V}$ for $\mathrm{C}_{6} \mathrm{H}_{5} \mathrm{CH}_{2} \mathrm{NH}_{3}^{+}$and $\mathrm{C}\left(\mathrm{CH}_{3}\right)_{3} \mathrm{C}_{6} \mathrm{H}_{4} \mathrm{CH}_{2} \mathrm{NH}_{3}^{+}$, respectively). The parent ions were then selected for MS/MS measurements. Each parent ion peak was examined at 20 different collision voltages (regularly spaced between 1.0 and $20.0 \mathrm{~V}$ ) and the fragment peaks were measured between $\mathrm{m} / \mathrm{z} 20$ and 200. The MS/MS runs, lasting $3 \mathrm{~min}$, were cycled repeatedly through the 20 collision voltages to enhance the reproducibility of the relative peak intensities at the different voltages. Argon was used as the collider gas. Parent and daughter ion peak intensities were recorded as functions of the collision voltage at several fixed pressures of the collider gas in the range $0.0-0.53 \mathrm{~Pa}(0.0-4.0 \mathrm{mTorr})$. The zero of the collision voltage scale was verified by observing the effects of stopping voltages on the ion signal in the absence of the collider gas.

The collision cell was comprised of a hexapole ion guide with the pole diameter of $5.0 \mathrm{~mm}$ and the inscribed diameter of $8.9 \mathrm{~mm}$. The hexapole was enclosed in a $25.5 \mathrm{~mm}$ i.d. cylindrical stainless steel housing (122.9 mm long). Identical $1.8 \mathrm{~mm}$ i.d. entrance and exit orifices were located at the ends of the cylinder. The length of the poles of the hexapole was $120 \mathrm{~mm}$. The peak amplitude of the radio frequency (rf) power applied to the poles of the hexapole was linearly scaled with the mass setting of the first quadrupole $(250 \mathrm{~V}$ zero to peak at $m / z=2000 \mathrm{Da}, 840 \mathrm{kHz}$, setting set up by the instrument manufacturer), resulting in $13.5 \mathrm{~V}$ for experiments on reaction 1 and $20.5 \mathrm{~V}$ for those on reaction 2.

The major product ions observed in the experiments were those of reactions 1 and 2, at mass numbers of 91 and 147. In the benzylammonium experiments, formation of ions at $m / z=65$ and 41 assigned to the products of secondary decomposition of $\mathrm{C}_{6} \mathrm{H}_{5} \mathrm{CH}_{2}^{+}$was also observed in minor amounts. These products were responsible for less than $2.5 \%$ of the total ion signal at collision energies of $15 \mathrm{eV}$ or less but their contribution increased at highest collision energies reaching $18 \%$ at $20 \mathrm{eV}$ and the pressure of $0.53 \mathrm{~Pa}$ ( $4.0 \mathrm{mTorr})$. In the 4-tert-butyl benzylammonium experiments, secondary product ion fragmentation yielding ions at $m / z 119$ and 132 was more pronounced, contributing less that $1.2 \%$ at collision energies of $10 \mathrm{eV}$ or less, and reaching up to $17 \%$ and $62 \%$ of the total ion signal at the collision energies of 15 and $20 \mathrm{eV}$, respectively, and the highest collision cell pressure of $0.53 \mathrm{~Pa}$ (4.0 mTorr).

The results were expressed in the form of parent ion fragmentation efficiency $x\left(E_{\mathrm{KIN}}, P\right)$ calculated as the ratio of the sum of all product ion signals to the sum of all ion signals, which includes the product and the parent ion:

$$
x\left(E_{\text {KIN }}, P\right)=\frac{\sum S_{i}}{\sum_{\text {PRODUCTS }} S_{i}}
$$

Here, ion signals $S_{i}$ were measured at the $m / z$ values corresponding to the respective peak maxima. $E_{\mathrm{KIN}}$ and
$P$ are the collision energy (kinetic energy of the parent ion upon entering the collision cell) and the gas pressure in the cell.

The results are presented in Figures 1 and 2 together with the results of modeling (see below). Upped plots in both figures show energy-dependent fragmentation efficiency curves obtained at different pressures; lower plots present the dependences of the fragmentation efficiency on the pressure for a numbers of selected values of the ion kinetic energy $(3-20 \mathrm{eV})$.

As can be seen from the plots, $x\left(E_{\mathrm{KIN}}, P\right)$ dependences are represented by $S$-shaped curves, with zero or almost zero fragmentation at low collision energies,

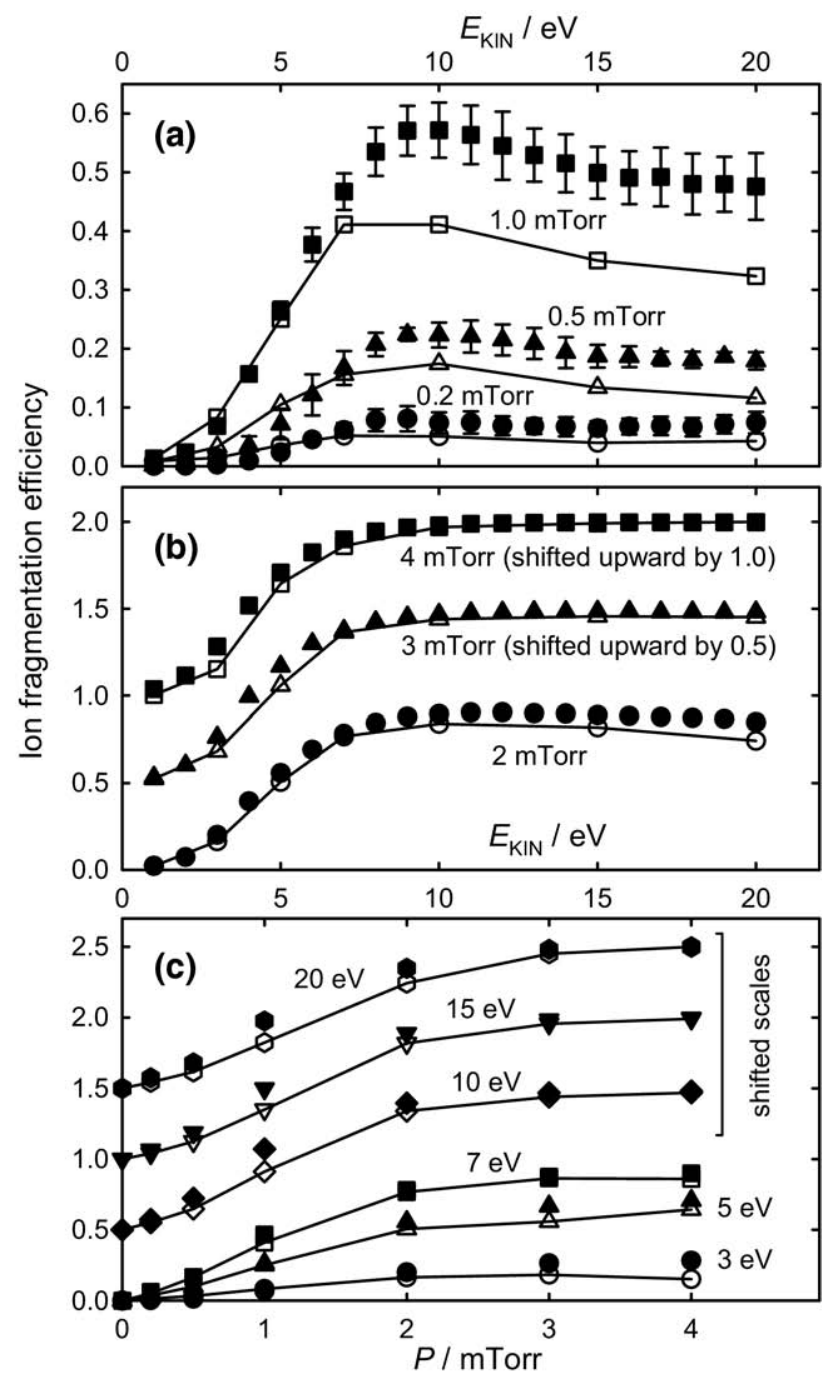

Figure 1. Experimental (closed symbols) and calculated (open symbols and lines) dependences of the benzylammonium ion fragmentation efficiency on the kinetic energy of the ion, $E_{\mathrm{KIN}}$ [parts (a) and (b)], and on the pressure in the collision cell [part (c)]. The "best agreement" model was used in the calculations $\left(T_{\text {INT }}=600 \mathrm{~K}, \Delta \mathrm{H}_{0}^{0}(1)=137.1 \mathrm{~kJ} \mathrm{~mol}^{-1}, T_{\mathrm{TR}}=600 \mathrm{~K}\right.$, see text $)$. Plots for 0.40 and $0.53 \mathrm{~Pa}$ (3.0 and $4.0 \mathrm{mTorr}$ ) in part (b) and those for 10,15 , and $20 \mathrm{eV}$ in part (c) are shifted in the vertical direction by successive increments of 0.5 to avoid crowding of the data points. Error bars show standard deviations from multiple measurements. 


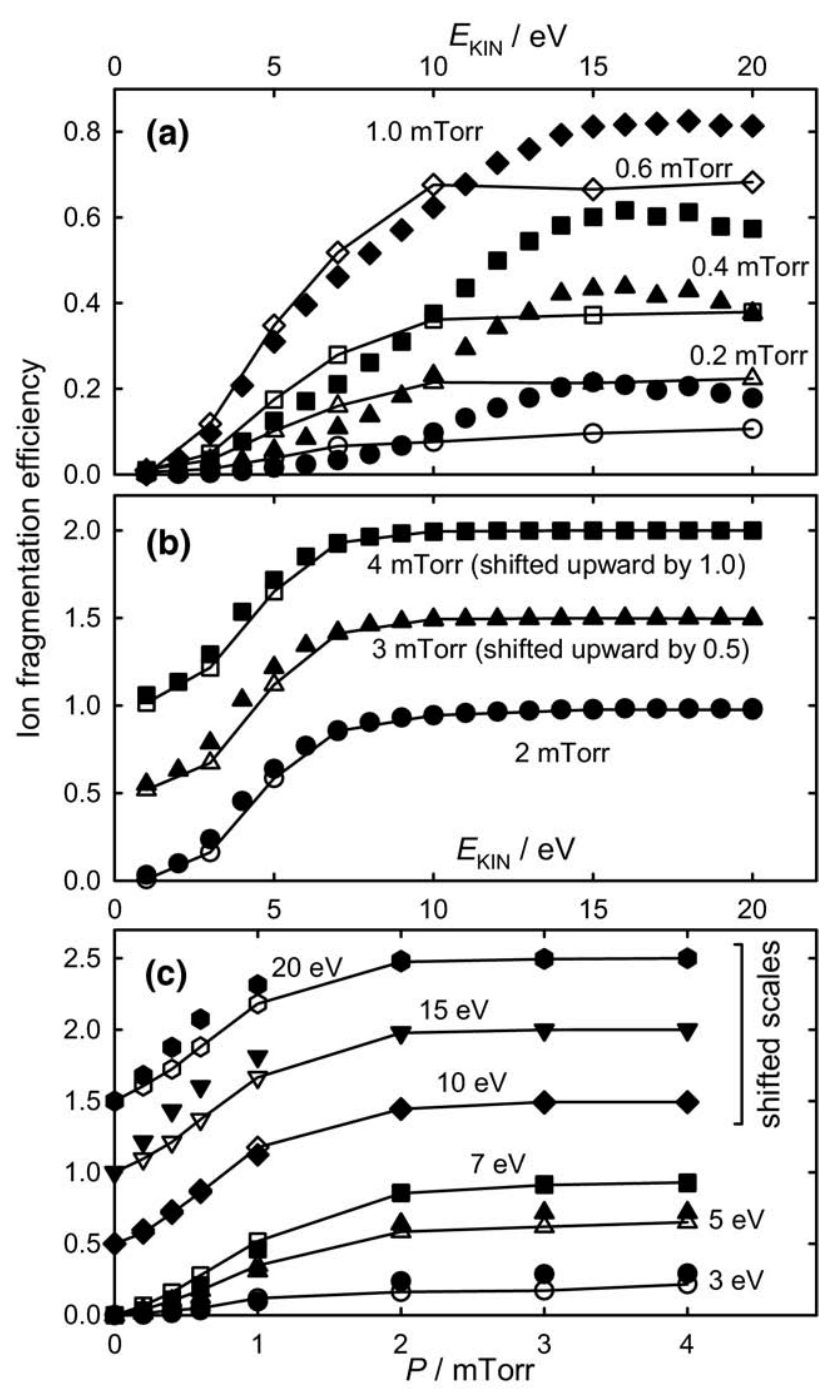

Figure 2. Experimental (closed symbols) and calculated (open symbols and lines) dependences of the 4-tert-butyl benzylammonium ion fragmentation efficiency on the kinetic energy of the ion, $E_{\mathrm{KIN}}$ [parts (a) and (b)], and on the pressure in the collision cell [part (c)]. Plots for 0.40 and $0.53 \mathrm{~Pa}$ (3.0 and $4.0 \mathrm{mTorr})$ in part (b) and those for 10,15 , and $20 \mathrm{eV}$ in part (c) are shifted in the vertical direction by successive increments of 0.5 to avoid crowding of the data points.

sharp rise between $\sim 2$ and $7 \mathrm{eV}$ (for reaction 1, between $\sim 2 \mathrm{eV}$ and $15 \mathrm{eV}$ for reaction 2), and then leveling off or slow decrease at higher energies. Curves obtained at low pressures $(0.027-0.27 \mathrm{~Pa}$, or $0.2-2$ mTorr) generally reach a fragmentation efficiency maximum of less than $100 \%$ and then demonstrate a weak decline at high $E_{\mathrm{KIN}}$ values; those obtained at higher pressures reach saturation at $100 \%$ fragmentation efficiency without any further decline. Incomplete fragmentation observed at low pressures despite high collision energies generally corresponds to the conditions where a fraction of parent ions passes through the collision cell without undergoing a single collision with the gas.

Average numbers of collisions experienced by the ions under different conditions in the collision cell are not easily determined because of the uncertainty in the definition of a collision event, as well as involvement of the processes of scattering and decomposition of ions. However, for the purposes of qualitative analysis of conditions, a rough estimate based on the equation $N_{\text {COLL }}=\sigma n l$ can be used for the average number of collisions per parent ion reaching the end of the collision cell. Here, $\sigma$ is the effective collisional cross section, $n$ is the concentration of the collider gas, and $l$ is the length of the collision cell. Using an estimated effective collision radius of $4.5 \AA$ for benzylammonium-argon collisions, one obtains $N_{\mathrm{COLL}}=0.5$ for the lowest pressure of $0.027 \mathrm{~Pa}(0.2 \mathrm{mTorr})$, and $N_{\mathrm{COLL}}=6.4$ for the highest pressure used, $0.53 \mathrm{~Pa}$ (4.0 mTorr).

A mode of presentation of the results alternative to that used in Figures 1 and 2 is to plot the effective reaction cross sections $\sigma_{\mathrm{R}}$ obtained using the equation $\left(1-x\left(E_{\mathrm{KIN}}, P\right)\right)=\exp \left(-\sigma_{\mathrm{R}} n l\right)$ as functions of the ion kinetic energy. For the conditions of single collisions, the effective reaction cross sections formalism provides more direct connection with the individual act of collisional excitation and decomposition of the ion. However, under the conditions of multiple collisions the values of effective reaction cross sections do not represent per-collision quantities and thus are pressure dependent and less useful. For illustrative purposes, examples of plots of the $\sigma_{\mathrm{R}}$ versus $E_{\mathrm{KIN}}$ dependences obtained for reaction 1 at the pressures of $0.027,0.13$, and $0.53 \mathrm{~Pa}(0.2,1.0$, and $4.0 \mathrm{mTorr})$ are presented in the Supporting Information (Figure 1S, which can be found in the electronic version of this article).

\section{Model}

\section{Potential Energy Surfaces}

The potential energy surfaces (PES) of reactions 1 and 2 were studied using quantum chemical methods. Energy optimization was performed using the density functional theory (DFT) method with the BH\&HLYP $[49,50]$ functional and, for reaction 1, single-point energy values were calculated using the $\operatorname{CCSD}(\mathrm{T})$ method [51-53]. The aug-cc-pvdz basis set [54] was used in all calculations. A version of the BH\&HLYP functional implemented in the Gaussian 03 program $[48,55]$ was used (Gaussian 03 was used in all PES calculations) which, as described in the program manual, is different from that of [49]. The choice of the BH\&HLYP functional was based on the reported positive results of using this method for studies of the properties of transition states (see, for example, references [56-61]). In the case of reaction 2 the sizes of the species involved prevented the use of the $\operatorname{CCSD}(\mathrm{T})$ method. Thus, $0 \mathrm{~K}$ reaction enthalpy was calculated using the method of isodesmic reactions (see below) and the energy of the transitionstate (PES saddle point) was obtained using the RESLIR method [62].

The minimum energy path for the reaction of decomposition of the benzylammonium ion passes through a 
saddle point with the energy lower than that of the completely separated $\mathrm{NH}_{3}+\mathrm{C}_{7} \mathrm{H}_{7}^{+}$products. The reaction path proceeding through this saddle point leads to a shallow PES minimum corresponding to a weakly bound $\mathrm{NH}_{3}-\mathrm{C}_{7} \mathrm{H}_{7}^{+}$complex (denoted as $\mathrm{C}_{7} \mathrm{H}_{7}^{+}\left[\mathrm{NH}_{3}\right]$ henceforth), which can decompose into $\mathrm{NH}_{3}$ and $\mathrm{C}_{7} \mathrm{H}_{7}^{+}$ via a very "loose" [63-66] transition-state. The PES of reaction 1 obtained in quantum chemical calculations and the shape of the transition-state and the complex are illustrated in Figure 3. Here and henceforth, the term "transition-state" given without any additional qualifiers denotes the PES saddle point located on the reaction path between the equilibrium configuration of the parent ion and the weakly bonded $\mathrm{C}_{7} \mathrm{H}_{7}^{+}\left[\mathrm{NH}_{3}\right]$ complex.

The PES of reaction 2 has the same qualitative shape. The energy of the products relative to that of the reactants ( $0 \mathrm{~K}$ reaction enthalpy) was evaluated by correcting the $\Delta \mathrm{H}_{0}^{0}$ of reaction 1 obtained at the $\operatorname{CCSD}(\mathrm{T}) /$ aug-ccpvdz//BH\&HLYP/aug-cc-pvdz level by the $0 \mathrm{~K}$ enthalpy of the isodesmic reaction

$$
\begin{aligned}
& \mathrm{C}\left(\mathrm{CH}_{3}\right)_{3} \mathrm{C}_{6} \mathrm{H}_{4} \mathrm{CH}_{2} \mathrm{NH}_{3}^{+}+\mathrm{C}_{6} \mathrm{H}_{5} \mathrm{CH}_{2}^{+} \\
& \quad \rightarrow \mathrm{C}\left(\mathrm{CH}_{3}\right)_{3} \mathrm{C}_{6} \mathrm{H}_{4} \mathrm{CH}_{2}^{+}+\mathrm{C}_{6} \mathrm{H}_{5} \mathrm{CH}_{2} \mathrm{NH}_{3}^{+}
\end{aligned}
$$

calculated at the less computationally expensive BH\&HLYP/aug-cc-pvdz level (-28.7 kJ mol ${ }^{-1}$, electronic energy only). This application of the isodesmic reaction method for reaction 2 is equivalent to obtaining the enthalpy of reaction 2 by using the high-level $\Delta \mathrm{H}_{0}^{0}$ of reaction 1 and correcting it by the difference between $\Delta \mathrm{H}_{0}^{0}(2)$ and $\Delta \mathrm{H}_{0}^{0}(1)$ obtained at the lower computational level (i.e., $\Delta \mathrm{H}_{0}^{0}(2)=\Delta \mathrm{H}_{0}^{0}(1, \mathrm{CCSD}(\mathrm{T}))+\Delta \mathrm{H}_{0}^{0}(4, \mathrm{DFT})=$ $\left.\Delta \mathrm{H}_{0}^{0}(1, \mathrm{CCSD}(\mathrm{T}))+\left(\Delta \mathrm{H}_{0}^{0}(2, \mathrm{DFT})-\Delta \mathrm{H}_{0}^{0}(1, \mathrm{DFT})\right)\right)$. The energy of the weakly bound $\mathrm{C}\left(\mathrm{CH}_{3}\right)_{3} \mathrm{C}_{6} \mathrm{H}_{4} \mathrm{CH}_{2}^{+}\left[\mathrm{NH}_{3}\right]$

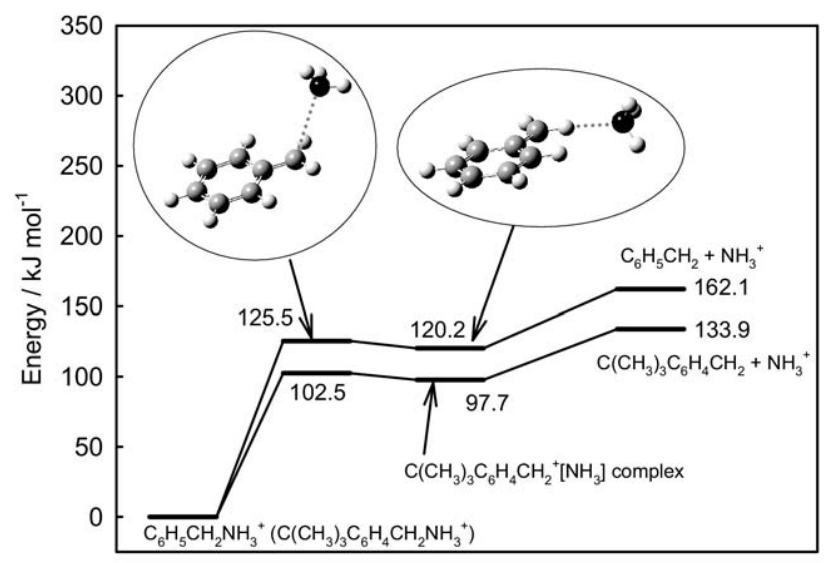

Reaction coordinate

Figure 3. The potential energy surfaces of reactions 1 and 2 obtained in quantum chemical calculations. In modeling the decomposition of $\mathrm{C}_{6} \mathrm{H}_{5} \mathrm{CH}_{2} \mathrm{NH}_{3}^{+}$, the values of $\Delta \mathrm{H}_{0}^{0}(1)$, energy of the transition-state, and that of the $\mathrm{C}_{7} \mathrm{H}_{7}^{+}\left[\mathrm{NH}_{3}\right]$ complex had to be lowered by $25 \mathrm{~kJ} \mathrm{~mol}^{-1}$ to achieve agreement between calculations and experiment (see text). The same adjustment by $25 \mathrm{~kJ} \mathrm{~mol}^{-1}$ was applied to the analogous parts of the PES of reaction 2. intermediate was also obtained by correcting the $\operatorname{CCSD}(\mathrm{T})$-level value obtained for the corresponding intermediate of reaction 1 by the DFT-level difference between $\mathrm{C}\left(\mathrm{CH}_{3}\right)_{3} \mathrm{C}_{6} \mathrm{H}_{4} \mathrm{CH}_{2}^{+}\left[\mathrm{NH}_{3}\right]$ and $\mathrm{C}_{6} \mathrm{H}_{5} \mathrm{CH}_{2}^{+}\left[\mathrm{NH}_{3}\right]$ (all energies are relative to those of the corresponding parent ions). The energy of the transition-state of reaction 2 was obtained via the RESLIR $(C C S D(T) / /$ BH\&HLYPBH\&HLYP/aug-cc-pvdz) method [62] based on application of the formalism of isodesmic reactions to transition states.

The calculated $\Delta \mathrm{H}_{0}^{0}$ of reaction $1,162.1 \mathrm{~kJ} \mathrm{~mol}^{-1}$, is in agreement with the $\Delta \mathrm{H}_{0}^{0}$ value estimated from the known thermochemical properties of the species involved, $150 \pm 16 \mathrm{~kJ} \mathrm{~mol}^{-1}$. The latter value was obtained using the standard enthalpies of formation of $\mathrm{C}_{6} \mathrm{H}_{5} \mathrm{CH}_{2} \mathrm{NH}_{3}^{+}\left(704.5 \pm 10.7 \mathrm{~kJ} \mathrm{~mol}^{-1}\right), \mathrm{C}_{6} \mathrm{H}_{5} \mathrm{CH}_{2}^{+}(105.7 \pm$ $\left.4.6 \mathrm{~kJ} \mathrm{~mol}^{-1}\right)$, and $\mathrm{NH}_{3}\left(-45.9 \pm 0.6 \mathrm{~kJ} \mathrm{~mol}^{-1}\right.$ [67]); these data for the ions were calculated using the values of heats of formation of the neutral species [67-69], the ionization energy of $\mathrm{C}_{6} \mathrm{H}_{5} \mathrm{CH}_{2}$ [70], and the proton affinity of benzylamine [71]. Here, the uncertainties in all thermochemical parameters were treated as systematic, and thus propagated through linear combination [72]. An alternative, "randomatic" method of propagation of errors based on treating all uncertainties as describable by statistical techniques [72] would require combining uncertainties in quadrature. Application of this method yields a lower value of uncertainty in $\Delta \mathrm{H}_{0}^{0}$ of reaction $1, \pm 9.4 \mathrm{~kJ} \mathrm{~mol}^{-1}$, which, in our opinion, is an underestimation. As described below, the values of $\Delta \mathrm{H}_{0}^{0}(1)$, energy of the transition-state, and that of the $\mathrm{C}_{7} \mathrm{H}_{7}^{+}\left[\mathrm{NH}_{3}\right]$ complex had to be lowered by $25 \mathrm{~kJ} \mathrm{~mol}^{-1}$ in modeling the decomposition of $\mathrm{C}_{6} \mathrm{H}_{5} \mathrm{CH}_{2} \mathrm{NH}_{3}^{+}$to achieve agreement between calculations and experiment. The resultant $\Delta \mathrm{H}_{0}^{0}(1)=137.1 \mathrm{~kJ} \mathrm{~mol}^{-1}$ is also within the range of uncertainty of the experimental value (but outside the range of uncertainty calculated by the randomatic method of propagation of errors).

\section{Collisional Excitation and Dissociation of Ions and Their Flight Through the rf-Only Hexapole Collision Cell}

Modeling of the processes of ion flight through the hexapole and their collisional excitation and dissociation was aimed at most closely reproducing the experimentally obtained quantities, i.e., ion counts of the parent and the product ions. It was assumed that the combination of the second quadrupole and the ion detector has the same sensitivity to all ions irrespective of their masses and chemical identities. Thus, modeling of the events occurring in the hexapole concentrated on the amounts of the parent and the product ions leaving the hexapole assembly through the exit aperture.

The Monte Carlo algorithm used is described in the diagram in Figure 4. An overview of the algorithm is given here and details of individual modeling steps are provided below. In the diagram, computational proce- 


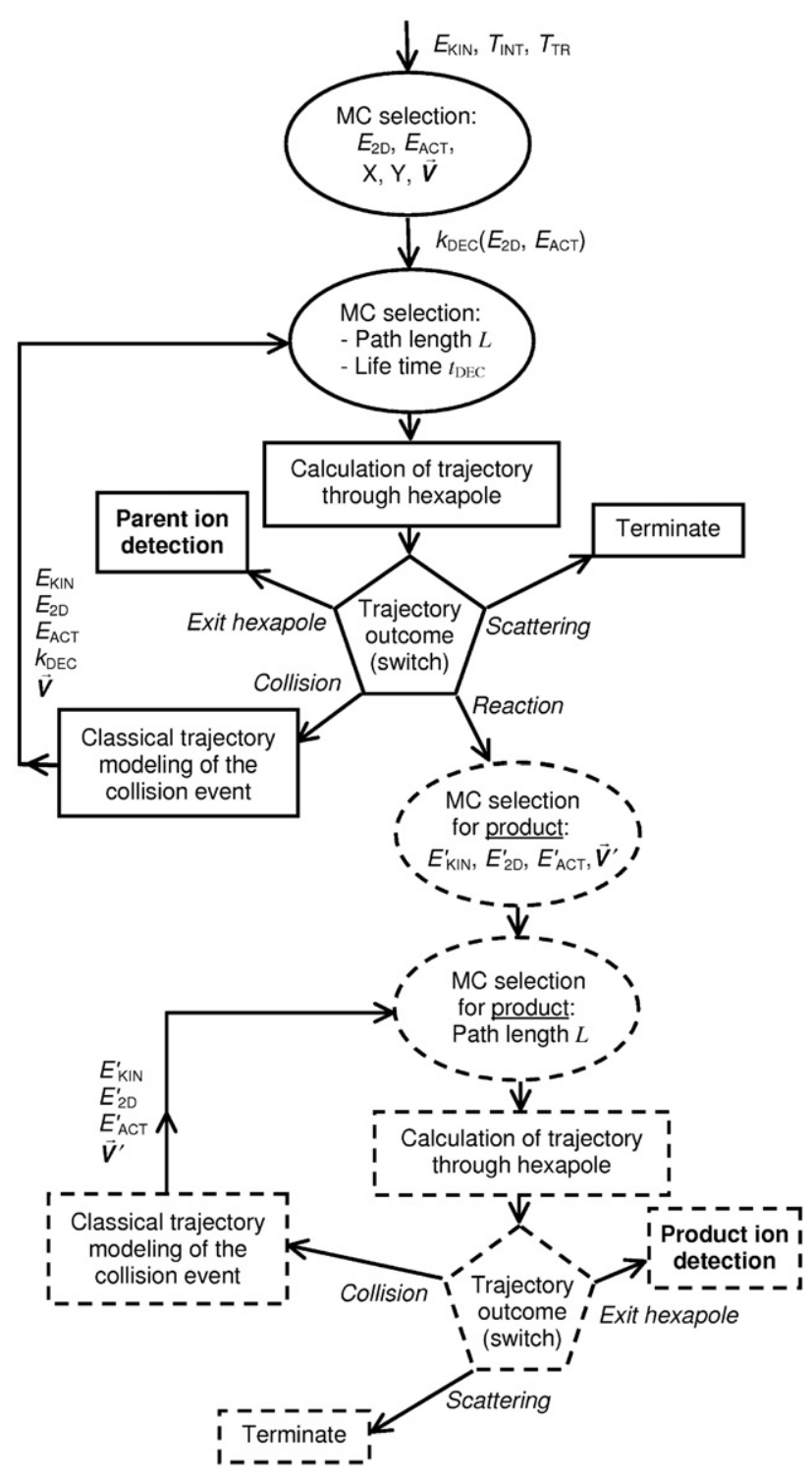

Figure 4. The Monte Carlo algorithm used in modeling of collisional excitation and dissociation of ions and their flight through the rf-only hexapole collision cell.

dures and operations (e.g., computing ion trajectory or counting ion as detected) are represented with rectangles; Monte Carlo selection of important parameters is represented with ovals, and logical switches based on outcomes of calculated ion trajectories are shown as pentagons.

Ions entering the hexapole through the entrance aperture are assumed to have an energy distribution characterized by an internal temperature $T_{\text {INT }}$ and a distribution of velocities orthogonal to the axis of the mass spectrometer described by an effective translational temperature $T_{\mathrm{TR}}$. Each individual ion entering the collision cell is assigned the following parameters: the kinetic energy of the motion along the cell axis $E_{\mathrm{KIN}}$, the energy of the active degrees of freedom (all degrees of freedom except the overall two-dimensional rotation, see references [64-66]) $E_{\mathrm{ACT}}$, the energy of the two- dimensional "adiabatic" overall rotation $E_{2 \mathrm{D}}$, the components of the ion velocity vector $\vec{V}$ (in the stationary system of coordinates), and the coordinates of the ion in the plane of the entrance aperture $(X, Y)$. Here, the value of the ion kinetic energy upon entering the collision cell $\left(E_{\mathrm{KIN}}\right)$ was fixed and any distribution of $E_{\mathrm{KIN}}$ (characteristic of real instruments) was ignored. $E_{\mathrm{ACT}}$ and $E_{2 \mathrm{D}}$ were obtained using Monte Carlo selection from a thermal distribution corresponding to $T_{\text {INT }}$. The component of $\vec{V}$ directed along the cell axis, $V_{Z}$, was determined by the value of $E_{\mathrm{KIN}}$; those orthogonal to the cell axis, $V_{X}$ and $V_{Y}$, were obtained via Monte Carlo selection from a thermal distribution corresponding to $T_{\mathrm{TR}}$. $\mathrm{X}$ and $\mathrm{Y}$ were randomly selected within the aperture. During the flight through the collision cell, the ion is always characterized by these parameters, which undergo evolution as a result of interaction with the rf electromagnetic field and collisions with the collider gas. If the active energy is sufficiently high, the ion can undergo decomposition with a rate constant $k_{\mathrm{DEC}}$ which depends on the values of $E_{\mathrm{ACT}}$ and $E_{2 \mathrm{D}}$. Thus, a value of $k_{\mathrm{DEC}}$ is always assigned zero in the case of low energies and non-zero (calculated from $E_{\mathrm{ACT}}$ and $E_{2 \mathrm{D}}$ ) in the case of energy sufficient to overcome the barrier to decomposition. A detailed description of the RRKM model used to calculate $k_{\mathrm{DEC}}$ and differentiation of degrees of freedom as active or adiabatic is given below.

Each Monte Carlo trial begins with an ion characterized by $E_{\mathrm{KIN}}, E_{\mathrm{ACT}}, E_{2 \mathrm{D}}, k_{\mathrm{DEC}}, \mathrm{X}, \mathrm{Y}$, and $\vec{V}$ entering the collision cell. At this point, the ion path length $L$ and life time with respect to reaction (decomposition) $t_{\mathrm{DEC}}$ are selected in a Monte Carlo procedure based on the values of the concentration of the collider gas and the rate constant of decomposition (the second oval from the top in Figure 4$)$. In the beginning of the trial $k_{\mathrm{DEC}}$ is zero and $t_{\mathrm{DEC}}$ is infinity. However, the automatic link between $k_{\mathrm{DEC}}$ and $t_{\mathrm{DEC}}$ values is present here because this step of the algorithm is repeated via a loop later, with higher values of internal energy and non-zero $k_{\mathrm{DEC}}$. Then, in the next step of the algorithm, a trajectory of the ion flight through the collision cell is calculated using integration of the classical equations of motion of a charged particle in electromagnetic field (see below). The trajectory continues until either the travel length $L$ or the time $t_{\mathrm{DEC}}$ is reached. The following outcomes of this trajectory calculation are possible (see notations on the diagram): "Scattering," "Exit hexapole," "Collision" with the collider gas, and "Reaction." "Scattering" means that the trajectory of the ion takes it outside the central region of the cell and the ion strikes one of the poles or the housing of the cell. In this case, the trial is terminated and the ion does not contribute to either the parent or the product signals. Exiting the collision cell ("Exit hexapole") means that ion reached the end of the collision cell and exited through the exit aperture. In this case the ion is counted as contributing to the parent ion signal ("Parent ion detection" in the diagram). If the ion reaches the end of the collision cell but strikes the 
part of the housing perpendicular to the axis of the cell, this event counts as "Scattering."

"Collision" means that the ion collided with an atom of the collider gas. In this case, the collision event is modeled via quasiclassical trajectory calculation. This type of trajectory calculation is different from that used above in that the modeled event occurs on a significantly shorter time scale and the interaction defining the process is not that of a point charge with an electromagnetic field but of a polyatomic ion with an atom of the collider gas. Details of the ion-atom models and the computational procedures used are given below. After a collision occurred and its characteristics were calculated (see below), the algorithm is looped into the first step, where the next values of the path length $L$ and life time $t_{\mathrm{DEC}}$ are selected.

The "Reaction" outcome of the trajectory run means that time equal to $t_{\mathrm{DEC}}$ was reached before the distance traveled exceeded the value of $L$. In this case, the parent ion is replaced with the product ion and the corresponding values of the kinetic energy, vibrational energy, energies of the adiabatic and active rotations, and components of the velocity vector $\left(E_{\mathrm{KIN}^{\prime}}^{\prime} E_{\mathrm{ACT}}^{\prime}, E_{2 \mathrm{D}}^{\prime}, \vec{V}\right)$ are calculated. Calculation of these quantities is performed via Monte Carlo selection from appropriate distributions of kinetic and internal energies of the ion and neutral reaction products obtained using the "prior distribution" model [73] and the laws of conservation of energy and momentum. Trajectory of the product ion flight through the collision cell is then calculated using the same methodology that was applied to the parent ion, with the possibility of reaction excluded. The corresponding components of the Monte Carlo algorithm are represented in Figure 4 with ovals, rectangles, and pentagons with borders drawn using dashed lines. The product ion can undergo collisions with the gas, with the poles or walls of the collision cell, or exit the cell through the exit aperture. In the latter case the ion is counted as contributing to the product ion signal ("Product ion detection" in the diagram).

Typically, ten thousand Monte Carlo trials were performed for each set of conditions, i.e., ion kinetic energy and pressure in the collision cell. The results were expressed in the form of fragmentation efficiency $x\left(E_{\mathrm{KIN}}, P\right)$ : the ratio of the number of the product ions leaving the collision cell to the numbers of all (parent and product) ions leaving the cell through the exit aperture.

RRKM models of ion decomposition. The RRKM models of ion decomposition were based on the potential energy surfaces of reactions 1 and 2 described above (Figure 3). The minimum energy path for reaction 1 proceeds through the transition-state with energy below that of the products to a shallow-minimum complex formed by $\mathrm{NH}_{3}$ and $\mathrm{C}_{6} \mathrm{H}_{5} \mathrm{CH}_{2}^{+}$. The complex can dissociate via a "loose" [63-66] transition-state into ammonia and the benzylium ion. The dynamic bottle- neck of the reaction was assumed to be positioned at the PES saddle point, i.e., the transition-state leading to the complex. Microcanonical rate constants $k\left(E_{\mathrm{ACT}}, E_{2 \mathrm{D}}\right)$ depending on the energy in the active degrees of freedom $\left(E_{\mathrm{ACT}}\right)$ and that of the two-dimensional overall adiabatic rotation $\left(E_{2 \mathrm{D}}\right)$ were calculated using the RRKM method [64-66]. Active degrees of freedom were assumed to include all vibrations, internal rotors, and one overall rotation with the smallest moment of inertia, in both the excited parent ion and the transitionstate [64-66]. To ensure that only ions possessing internal energy sufficient to overcome the $0 \mathrm{~K}$ enthalpy of the reaction contribute to the overall reaction rate, all values of $k\left(E_{\mathrm{ACT}}, E_{2 \mathrm{D}}\right)$ were set to zero for $E_{\mathrm{ACT}}+E_{2 \mathrm{D}}<$ $\Delta H_{0}^{0}(1)$. This criterion is based on the fact that ions possessing $E_{\mathrm{ACT}}$ that is below $\Delta H_{0}^{0}(1)$ but larger than the energy of the PES saddle point may still contribute to the reaction provided that they have sufficiently large $E_{2 \mathrm{D}}$, i.e., if they overcome the centrifugal barrier $[65,66]$ for the reaction. The centrifugal barrier is determined by the value of $E_{2 \mathrm{D}}$, the moments of inertia of the benzylammonium ion, and the dependence of the potential energy and the two-dimensional moment of inertia of the decomposing $\mathrm{C}_{7} \mathrm{H}_{7}^{+}\left[\mathrm{NH}_{3}\right]$ complex on the distance between the separating products, $\mathrm{C}_{7} \mathrm{H}_{7}^{+}$and $\mathrm{NH}_{3}$. Detailed accurate PES information needed for exact calculation of the centrifugal barrier values is not available. However, given that the moment of inertia of the long-range effective transition-state for the decomposition of the $\mathrm{C}_{7} \mathrm{H}_{7}^{+}\left[\mathrm{NH}_{3}\right]$ complex can be expected to be significantly larger than that of the $\mathrm{C}_{6} \mathrm{H}_{5} \mathrm{CH}_{2} \mathrm{NH}_{3}^{+}$ ion, the overall (potential energy plus centrifugal) barrier can be estimated as $\Delta H_{0}^{0}(1)-E_{2 \mathrm{D}}$. Thus, the condition for an ion to be able to overcome this total barrier becomes $E_{\mathrm{ACT}}>\Delta H_{0}^{0}(1)-E_{2 \mathrm{D}}$, which coincides with the criterion given above.

The model of reaction 2 is similar to that of reaction 1 , with differences in the energies of the optimized structures of the PES and vibrational and rotational properties of the species involved. The details of the models (geometries of the species, vibrational frequencies, rotational constants, and energies) are given in the Supporting Information.

A modification of the model of reaction 1 was introduced in an attempt to achieve better agreement between the experimental and the calculated fragmentation efficiency curves: the value of $0 \mathrm{~K}$ reaction enthalpy $\Delta H_{0}^{0}(1)$ was adjusted to $137.1 \mathrm{~kJ} \mathrm{~mol}^{-1}$. This modification is described in more detail and discussed below, in the Results and Discussion section.

Modeling of ion flight through the hexapole collision cell. Ion trajectories were calculated by numerically integrating the Newton's second law equation. Ion was approximated by a charged point mass. Equations given for an ideal hexapole in [70] were used to describe the coordinate and time dependence of the electric field in the collision cell. The time integration step was typically 12 ns $(1 / 100$ th of the rf period). It was assumed that 
collisions between the ion and the collider gas occur only inside the collision cell housing; presence of gas outside the collision cell in the vicinity of its entrance and exit orifices was ignored.

Modeling of ion collisions with the monoatomic collider gas and energy transfer. Quasiclassical trajectory calculations were performed to model the collisions of the ions with the monoatomic collider gas (argon) and the resulting energy-transfer and change in the value and direction of the ion's velocity. The program MARINER [74], which is a customized version of VENUS96 [75], was used in these calculations.

For the purpose of collision simulations, the potential energy surface of the ion was represented with a harmonic force field employing three types of terms: bond stretches, bends, and torsions. This method of PES representation is well described in the literature (e.g., [76-78]. AMBER [76] force field parameters were used as the source of force constants needed to describe the PES of the benzylammonium and the 4-tert-butyl benzylammonium ions. The intermolecular potential describing the interaction between the argon atom and the polyatomic ion was of the pairwise-additive type, where the overall potential energy function is given by a sum of distance-dependent potentials of interaction between $\mathrm{Ar}$ and all individual atoms of the ion. These inter-atomic potentials were represented by the exponential-ninth power expression

$$
V(R)=A \exp (-B \times R)+\frac{C}{R^{9}}
$$

Here, $R$ is the inter-atomic distance and $\mathrm{A}, \mathrm{B}$, and $\mathrm{C}$ are the parameters specific to each combination of atoms. The exponential term describes the long-range attractive part of the potential and the ninth-power term is responsible for the short-range repulsive part.

The parameters A, B, and C of inter-atomic interactions were taken from the work of Meroueh and Hase, [21], who used high-level quantum chemical calculations to evaluate the interactions between Ar atoms and the constituent atoms of small peptides. Since [21] did not include parameters for aromatic carbons and hydrogens, these were calculated using the procedure applied by Meroueh and Hase for other types of atoms. QCISD $(T) / 6-31++G(d, p)$ - level [79] calculations with counterpoise corrections $[75,80]$ were performed to determine the energy of interaction between Ar and benzene at various separations. The resultant potential energy curves were fitted with expression 5 to obtain the requisite parameters (given in Supporting Information).

The velocity of the relative ion-Ar motion was taken from the output of calculation of the trajectory of the ion flight through the collision cell and fed into the MARINER input. Thermal velocity of the Ar atom was added via a random selection from the Maxwell-Boltzmann distribution. Other input data transferred to the MARINER program were the energy of the two-dimensional overall rotation of the ion and its energy in the active degrees of freedom. The latter value was added to the zero-point energy calculated from the vibrational frequencies resulting from the force field representation of the ion PES. The initial impact parameter $b$ and the relative orientation of the ion-Ar pair were selected using Monte Carlo sampling. The $b$ parameter ranged from 0 to the maximum value of $b_{0}(8.0 \AA$ for $A r-$ benzylammonium and $10.0 \AA$ for Ar-4-tert-butyl benzylammonium collisions). These respective values of $b_{0}$ were used in calculating the cross section $\left(\pi b_{0}^{2}\right.$ for determining the probabilities of Ar-ion collisions in the Monte Carlo selection of the ion path length $L$ before modeling the ion flight through the hexapole (see above). Initial separation of the species in MARINER calculations was $15 \AA$; the integration time step was in the $0.1-0.3$ fs range.

For each event of an ion-Ar collision, an individual trajectory was calculated and the output of the MARINER program was fed to subsequent calculations within the same continuing simulation of an individual ion travel through the hexapole collision cell. The following data were transferred: the changes in $E_{2 \mathrm{D}}$ and $E_{\mathrm{ACT}}$ due to collision (usually, excitation of the ion, although deactivating collisions also occurred) and the changes in the value and the direction of the relative velocity of the colliding species (used to calculate $E_{\mathrm{KIN}}$ and $\vec{V}$ after the collision). The new value of $k_{\mathrm{DEC}}$ was calculated using the new values of $E_{2 \mathrm{D}}$ and $E_{\mathrm{ACT}}$; this value was later used in the Monte Carlo selection of the next life time $t_{\mathrm{DEC}}$ of the ion.

\section{Results and Discussion}

\section{Dissociation of Benzylammonium}

Internal energy and reaction enthalpy. The results of modeling of reaction 1 are highly sensitive to the values of the reaction enthalpy and the internal temperature of the ions. Thus, both were used as adjustable parameters that were varied to achieve agreement with the experimental ion fragmentation efficiency profiles. The best agreement was observed when the values of $T_{\text {INT }}=600$ $\mathrm{K}$ and $\Delta \mathrm{H}_{0}^{0}(1)=137.1 \mathrm{~kJ} \mathrm{~mol}^{-1}$ were used. In the process of varying and adjusting of these parameters, step sizes of $50 \mathrm{~K}$ and $5.0 \mathrm{~kJ} \mathrm{~mol}^{-1}$ were used for $T_{\text {INT }}$ and $\Delta \mathrm{H}_{0}^{0}(1)$, respectively. The limits of variation of $\Delta \mathrm{H}_{0}^{0}(1)$ were determined by a requirement that it should stay within the uncertainties of the experimental value (see above). When $\Delta \mathrm{H}_{0}^{0}(1)$ was varied, the energies of the transition-state of reaction 1 and of the $\mathrm{C}_{7} \mathrm{H}_{7}^{+}\left[\mathrm{NH}_{3}\right]$ complex relative to that of the products were fixed at the values obtained in quantum chemical calculations. It was observed that the calculated fragmentation efficiency curves displayed significantly lower sensitivity to variations in the position of the transition-state on the energy scale than to changes in $\Delta \mathrm{H}_{0}^{0}(1)$ and $T_{\mathrm{INT}}$. Also, varying the two lowest vibrational frequencies of the 
transition-state by a factor of two resulted in no visible effects on the fragmentation efficiency curves.

The effect of variations in $T_{\text {INT }}$ can be seen from the plots in Figure 5a, where the fragmentation efficiency curves calculated using different $T_{\text {INT }}$ are compared with the experimental data. Higher values of $T_{\text {INT }}$ result in shifting of the calculated curve to lower values of the ion kinetic energy and higher values of the maximum fragmentation efficiency. Decreasing $\Delta \mathrm{H}_{0}^{0}(1)$ has a similar effect, although the maximum value of the fragmentation efficiency is less sensitive to $\Delta \mathrm{H}_{0}^{0}(1)$ than it is to $T_{\text {INT. }}$. The selected combination of $T_{\text {INT }}$ and $\Delta H_{0}^{0}(1)$ was chosen based on the best overall agreement between the shapes of the calculated and the experimental curves. Most likely, this combination of $T_{\text {INT }}$ and $\Delta \mathrm{H}_{0}^{0}(1)$ is not

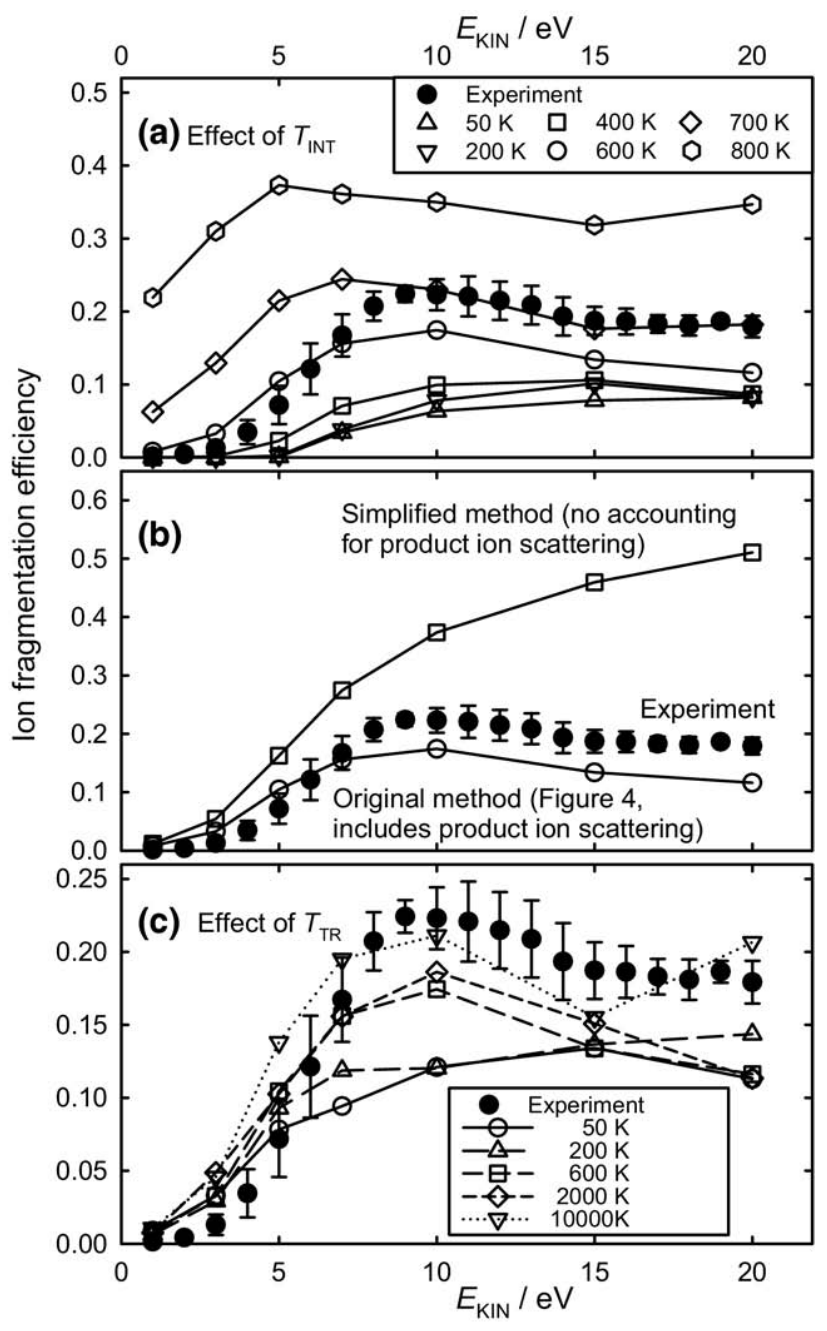

Figure 5. Effects of (a) the effective internal temperature of the ion $T_{\mathrm{INT}},(\mathbf{b})$ accounting for scattering of the product ions, and (c) the initial ion translational temperature $T_{\mathrm{TR}}$ on the calculated fragmentation efficiency curves. Calculated (open symbols) and experimental (closed circles) values of fragmentation efficiency of the benzylammonium ion are shown. The pressure in the collision cell is $0.067 \mathrm{~Pa}(0.5 \mathrm{mTorr})$ of argon. Error bars show standard deviations from multiple measurements. The "best agreement" model $\left(T_{\mathrm{INT}}=600 \mathrm{~K}, \Delta \mathrm{H}_{0}^{0}(1)=137.1 \mathrm{~kJ} \mathrm{~mol}^{-1}, T_{\mathrm{TR}}=600 \mathrm{~K}\right)$ was used in the calculations, with variations as indicated. unique; possibly other values can result in similar degree of agreement between theory and experiment, especially considering that other parameters of the model (e.g., the effective translational temperature and the entropy of the transition-state) can also be varied within reasonable ranges. The selected value of $\Delta \mathrm{H}_{0}^{0}(1)$, $137.1 \mathrm{~kJ} \mathrm{~mol}^{-1}$, is within the range of uncertainty of the experimental value, $150 \pm 16 \mathrm{~kJ} \mathrm{~mol}^{-1}$ (see above).

Effects of product ion scattering. The results of calculations demonstrate that accurate description of both reactant and product ion trajectories in the hexapole collision cell is important for modeling fragmentation efficiencies. Figure 5b displays the calculated fragmentation efficiency curves for the pressure of $0.067 \mathrm{~Pa}(0.5$ mTorr) obtained using two different methods. The first method is that described above; it follows the algorithm of Figure 4. The second method uses a simplified procedure, where ion trajectories are not followed completely through the collision cell but only to the point of occurrence of one of the following events: dissociation, scattering, or reaching the end of the cell. In the case of the second method, fragmentation efficiency is calculated as the ratio of the number of decomposed parent ions to the total number of parent ions entering the cell. The main difference between the first and the second methods is that in the first method, the ratio of numbers of ions passing through the exit aperture of the cell determines the value of the fragmentation efficiency and in the simplified second method this quantity is given by the ratio of the numbers of reacted ions to that of all parent ions in the cell.

As can be seen from the plots, the simplified method yields significantly larger values of fragmentation efficiency, indicating that, under these conditions, scattering of product ions is larger than that of the parent ions. In other words, the fraction of ions that pass through the exit aperture of the cell is smaller for the product ions than for the parent ions. This can be explained by the additional random-direction component of velocity acquired by the product ions through kinetic energy release in the reaction. The differences between the results of the simplified method and those of complete description of ion scattering appear to be more pronounced at high $E_{\mathrm{KIN}}$, most likely, due to larger vibrational excitation and thus larger excess energy released in the dissociation reaction. Thus, the qualitative shapes of the calculated fragmentation efficiency curves are different for the original and the simplified methods. Neglecting the differences in scattering between the parent and product ions results in fragmentation efficiency increasing monotonically with the ion kinetic energy. Taking these differences into account (in the original method) results in calculated curves that show rapid rise, saturation, and weak decline in the fragmentation efficiency versus ion kinetic energy dependences, reproducing the experimentally observed trends. 
Translational temperature of ions. Scattering of ions, both parent and product, is affected by the distribution of velocities orthogonal to the axis of the cell. The main parameter controlling this distribution in the current model is the translational ion temperature $T_{\mathrm{TR}}$. Figure $5 c$ demonstrates the effects of different values of translational temperature on the shapes of fragmentation efficiency curves at the pressure of $0.067 \mathrm{~Pa}(0.5 \mathrm{mTorr})$. In these calculations, the values of $T_{\text {INT }}=600 \mathrm{~K}$ and $\Delta \mathrm{H}_{0}^{0}(1)=137.1 \mathrm{~kJ} \mathrm{~mol}^{-1}$ were used. As can be seen from the plots, qualitative curve shapes change from monotonic increase with a trend towards saturation at low $T_{\mathrm{TR}}$ to, at larger $T_{\mathrm{TR}}$, faster growth at low $E_{\mathrm{KIN}}$, saturation, and slight decrease at higher $E_{\mathrm{KIN}}$. The latter behavior is more consistent with the observed experimental trends.

The actual distribution of orthogonal ion velocities is not known. To approximately evaluate this distribution, modeling of ion flight through the first quadrupole of the MS/MS apparatus, which supplies the ions entering the hexapole collision cell, was performed using the SIMION 7 program $[48,81]$. Actual parameters of the quadrupole mass spectrometer were used: $13.1 \mathrm{~cm}$ length, $1.20 \mathrm{~cm}$ rod diameter, $22.6 \mathrm{~mm}$ inscribed diameter, rf voltage $1.5 \mathrm{~V} / \mathrm{Da}, \mathrm{DC}$ voltage $\sim 1 / 6$ of the $\mathrm{rf}$ voltage. In the simulation process, ions were randomly and uniformly generated in the plane of the entrance aperture of the quadrupole and assigned random thermal velocities $(100 \mathrm{~K})$ and additional velocity in the direction of the quadrupole axis corresponding to the accelerating voltage of $5 \mathrm{~V}$. The results of the simulation indicate that ions exiting the quadrupole through the exit aperture (taken to be the same as the entrance aperture of the hexapole collision cell) have components of the velocity orthogonal to the axis of the cell that significantly exceed original thermal velocities. This orthogonal acceleration is the result of the action of the rf/DC field guiding the ions through the quadrupole. The distributions of the orthogonal component of the ion kinetic energy were non-thermal and best described with double-exponential functions, where the dominant $(\approx 90 \%)$ part can be described by an effective temperature of $\sim 800-1000 \mathrm{~K}$ and the minor $(\approx 10 \%)$ part by an effective temperature of $\sim 9000-13,000 \mathrm{~K}$. An example of such distribution is presented in Supporting Figure 2S. These orthogonal velocities, however, depended on the exact settings of the rf and DC components of the quadrupole voltages. Given the fact that these voltages are generally tuned to achieve optimal resolution and transmittance but not recorded, and that SIMION modeling was sensitive to the (unknown) initial distribution of the values and directions of ion velocities, as well as the positions of ion entry within the entrance aperture, the results of this modeling were used only in a qualitative way, as a confirmation that the orthogonal translational energies of ions entering the collision cell are large, corresponding to $T_{\mathrm{TR}}$ measured in hundreds or thousands of Kelvin. The value of $T_{\mathrm{TR}}$ was thus used as an adjustable parameter in the
Monte Carlo modeling of ion scattering and decomposition. As can be seen from the plots in Figure 5c, selecting higher $T_{\mathrm{TR}}$ generally resulted in somewhat larger fragmentation efficiencies. Thus, $T_{\mathrm{TR}}$ is coupled in the modeling process with $\Delta H_{0}^{0}$ and $T_{\text {INT }}$.

Calculated transmission properties of the hexapole cell at zero pressure (no collisions) also depend on the translational ion temperature. Supporting Figure 3S displays the zero-pressure experimental and the calculated dependences of the parent ion signal on $E_{\mathrm{KIN}}$. None of the calculated curves matches the experimental dependence exactly. The qualitative shape of the $600 \mathrm{~K}$ dependence, however, resembles the experimental curve somewhat better than the other dependences given on the plot.

In the working "best agreement" model, the value of $T_{\mathrm{TR}}=600 \mathrm{~K}$ was thus selected, which also results in a reasonable qualitative match between the shapes of the fragmentation efficiency versus pressure dependences. The selected combination of $T_{\mathrm{TR}}$ and the rest of model parameters is not unique; for example, using higher value of $T_{\mathrm{TR}}$ would result in somewhat larger values of calculated fragmentation efficiency and thus require a lower $T_{\text {INT }}$ or higher $\Delta \mathrm{H}_{0}^{0}(1)$ to bring the calculations into agreement with experiment.

Fragmentation efficiency dependence on the kinetic energy of ions. The calculated dependences of the ion fragmentation efficiency on $E_{\mathrm{KIN}}$ resulting from the use of the selected working model of reaction 1 are presented in Figure 1, together with the corresponding experimental dependences. Different plots correspond to different pressures of argon in the collision cell. As can be seen from the plots, the calculations generally adequately reproduce the energies at which the sharp rise of fragmentation efficiency occurs, although the agreement is somewhat poorer at low pressures, especially for reaction 2. The general shapes of the curves are also well reproduced: sharp rise followed by saturation (at higher pressures) or slow decline (at lower pressures). The absolute values of fragmentation efficiency are described somewhat less accurately. Deviations of the calculated dependences from the experimental ones are most noticeable at pressures where $100 \%$ dissociation is not achieved even at large $E_{\mathrm{KIN}}$ values, $P<0.27 \mathrm{~Pa}(2$ $\mathrm{mTorr}$ ). The agreement between the positions of the sharp rise of the fragmentation efficiency curves on the energy scale is expected since the properties of the model were fitted to reproduce experimental data. However, the agreement between the experimental and the calculated general shapes of the curves, including the slopes of the rising and decaying parts, is more important, as it indicates the ability of the used model of the ion-atom interaction to quantitatively describe the complex processes of collisional excitation of ions, their decomposition, and scattering of the parent and the products ions in the hexapole collision cell. The agreement between theory and experiment is further discussed below. 
Pressure dependence of the fragmentation efficiency. Figure $1 \mathrm{c}$ presents the experimental and the calculated dependences of the fragmentation efficiency on the pressure in the collision cell for a numbers of selected values of the ion kinetic energy (3-20 eV). Generally, experiment and theory are in satisfactory agreement. As was discussed above, the average number of collisions experienced by a parent ion traveling through the full the length of the collision cell can be roughly estimated as changing from $\sim 0.5$ at the lowest pressure used to $\sim 6$ at the highest pressure. Thus, the left part of the dependences presented in Figure 1c corresponds to the conditions of mostly single collisions and the right part-to those of multiple collisions.

\section{Dissociation of t-Butyl Benzylammonium}

Modeling of reaction 1, that of collisional dissociation of benzylammonium, demonstrated that certain parameters of the model had to be adjusted to achieve agreement with experiment. In particular, the reaction enthalpy $\Delta \mathrm{H}_{0}^{0}(1)$ and the effective internal temperature $T_{\text {INT }}$ were tuned; the value of $T_{\mathrm{TR}}=600 \mathrm{~K}$ was used. The next logical step of modeling is an attempt to use the same model, with the values of the above adjustable parameters selected on the basis of success of modeling of reaction 1, to another reaction with different activation parameters. Reaction 2 was selected for this purpose. Dissociation of $t$-butyl benzylammonium ion requires overcoming a smaller energy barrier compared to the barrier for dissociation of benzylammonium (Figure 3, a $28 \mathrm{~kJ}$ $\mathrm{mol}^{-1}$ difference). The number of active degrees of freedom of $t$-butyl benzylammonium (85) is larger than that of unsubstituted benzylammonium (49).

A model of reaction 2 was thus created using the model of reaction 1 as the basis. The $0 \mathrm{~K}$ reaction enthalpy, $\Delta \mathrm{H}_{0}^{0}(2)$, was adjusted relative to the value based on quantum chemical calculations by the same amount that was applied in the case of reaction 1: -25.0 $\mathrm{kJ} \mathrm{mol}^{-1}$, to the final selected value of $\Delta \mathrm{H}_{0}^{0}(2)=108.9 \mathrm{~kJ}$ $\mathrm{mol}^{-1}$. The energies of the transition-state (PES saddle point) and the $\mathrm{C}\left(\mathrm{CH}_{3}\right)_{3} \mathrm{C}_{6} \mathrm{H}_{4} \mathrm{CH}_{2}^{+}\left[\mathrm{NH}_{3}\right]$ intermediate relative to the $\mathrm{C}\left(\mathrm{CH}_{3}\right)_{3} \mathrm{C}_{6} \mathrm{H}_{4} \mathrm{CH}_{2}^{+}+\mathrm{NH}_{3}$ dissociation products remained unchanged. The value of $T_{\mathrm{TR}}=600$ $\mathrm{K}$ was used. Selection of the effective internal temperature, however, is not straightforward. The degree of internal vibrational excitation of the ion entering the collision cell is determined by the processes in the ion source. Since these processes are not expected to be characterized by thermal equilibrium, there is no reason to expect different ions to have the same effective internal temperature. A feasible model can be based on an assumption that, under identical conditions in the ion source, different ions participate in similar processes resulting in vibrational excitation and thus should have similar amounts of energy deposited in their degrees of freedom. Thus, the $t$-butyl benzylammonium ions entering the collision cell should have initial internal energy similar to that of the benzylam- monium ions. Scaling the value of $T_{\text {INT }}=600 \mathrm{~K}$ used for modeling the CID of the benzylammonium ions by the number of degrees of freedom will result in $T_{\mathrm{INT}}=350$ $\mathrm{K}$; such scaling corresponds to classical treatment of all degrees of freedom. Using the rovibrational models of these species and quantum expressions for energies of oscillators and rotors, one obtains the effective internal temperature $T_{\text {INT }}=430 \mathrm{~K}$.

Modeling of collision-induced dissociation of $t$-butyl benzylammonium was performed using these two values of $T_{\text {INT }}$. The results demonstrated that using the values of 350 and $430 \mathrm{~K}$ lead to under-prediction and over-prediction of ion dissociation, respectively. Use of the average value, $T_{\text {INT }}=390 \mathrm{~K}$ resulted in best agreement between experiment and calculations. The results of modeling are shown in Figure 2, in comparison with the experimental data. The agreement can be described as satisfactory, although somewhat poorer than in the case of reaction 1. The largest relative deviations of the calculated fragmentation efficiencies from the experimental values are observed at the low pressures and high ion kinetic energies $\left(E_{\mathrm{KIN}}=15-20 \mathrm{eV}\right)$. In particular, the experimental ion fragmentation efficiency versus $E_{\mathrm{KIN}}$ curves at lower pressures (Figure 2a) display slower growth to saturation compared to similar curves at higher pressures and those obtained for the benzylammonium ion. This trend is not reproduced by the model, which results in saturation at lower energies.

\section{Energy Distribution Functions}

Examples of energy distribution functions resulting from collisions between benzylammonium ion and argon atoms are presented in Figure 6. The upper plot (Figure 6a) illustrates the per-collision activation function, the probability of energy-transfer upon a collision with a collider gas atom with the relative kinetic energy $E_{\mathrm{COLL}}$. Here, the $\Delta E$ axis corresponds to the energy change; two plots are given, one for the energy in the active degrees of freedom $\left(E_{\mathrm{ACT}}\right)$ and another for that of the overall two-dimensional rotation $\left(E_{2 \mathrm{D}}\right)$. The shape of the $\Delta E_{\mathrm{ACT}}$ probability distribution in Figure 6a is qualitatively similar to those obtained by Meroueh and Hase [21] in quasiclassical trajectory studies of collisional excitation of small peptides. This general similarity can be expected since the quasiclassical trajectory methodology used in the calculations of the current work was based on that of Meroueh and Hase. It is interesting to note that both energy distributions have markedly nonthermal character, i.e., they cannot be approximated with a Boltzmann distribution without neglecting their distinctive shapes. Also, for illustrative purposes, Figure $4 S$ in the Supporting Information compares this distribution with the functional form of the internal energy distribution used by Armentrout and coworkers (e.g., refs [11, 20, 43-46]).

The two lower plots in Figure 6 show examples of distributions of energy in the active degrees of freedom $\left(E_{\mathrm{ACT}}\right)$ resulting from very few (Figure 6b) or many 

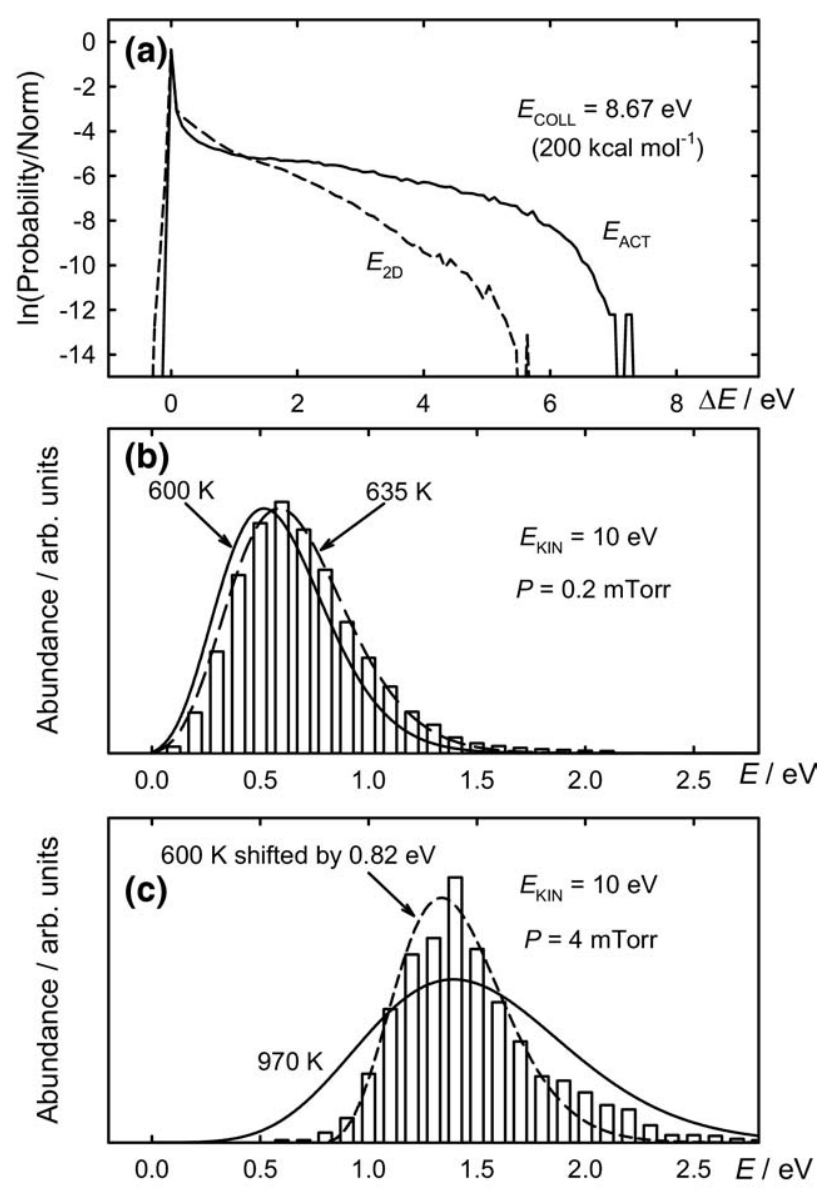

Figure 6. Energy distributions of benzylammonium ions obtained in calculations. (a) Examples of per-collision internal energy distributions (energy in the active degrees of freedom, $E_{\mathrm{ACT}}$, and that of the adiabatic two-dimensional rotation, $E_{2 \mathrm{D}}$ ) obtained in quasiclassical trajectory calculations. The center-of-mass kinetic energy $E_{\mathrm{COLL}}$ is $8.67 \mathrm{eV}\left(200 \mathrm{kcal} \mathrm{mol}^{-1}\right)$. Note that $E_{\mathrm{COLL}}$ differs from $E_{\mathrm{KIN}}$ by a factor determined by a ratio of masses: $E_{\mathrm{COLL}}=$ $\mathrm{m}(\mathrm{Ar}) /\left(\mathrm{m}(\mathrm{Ar})+\mathrm{m}\left(\mathrm{C}_{6} \mathrm{H}_{5} \mathrm{CH}_{2}^{+}\right)\right) \times E_{\mathrm{KIN}}$. (b) Energy distribution of benzylammonium ions corresponding to the ion trajectories reaching the exit aperture of the hexapole collision cell (see text) at the pressure of $0.027 \mathrm{~Pa}(0.2 \mathrm{mTorr})$. The bar plot represents the results of Monte Carlo modeling. Thermal Boltzmann energy distributions at selected temperatures are given for comparison (lines). (c) Same as in part (b) but for the pressure of $0.53 \mathrm{~Pa}(4.0 \mathrm{mTorr})$. The dashed line is for a Boltzmann distribution at $600 \mathrm{~K}$ shifted along the energy axis by $0.82 \mathrm{eV}$. Note the qualitatively different energy distribution shapes corresponding to single and multiple collisions per trajectory (the pressures of 0.027 and $0.53 \mathrm{~Pa}$, or 0.2 and 4 mTorr, respectively).

(Figure 6c) ion-argon collisions. These are distributions of benzylammonium ions corresponding to the ion trajectories reaching the exit aperture of the hexapole collision cell. This includes trajectories in which either unreacted parent ions or product ions of reaction 1 arrive at the exit of the cell. In the former case, the energy is the active energy $\left(E_{\mathrm{ACT}}\right)$ of the parent ion at the moment of leaving the cell; in the latter case, it is the value of $E_{\mathrm{ACT}}$ before the dissociation of the parent ion. The two lower panels in Figure 6 correspond to different conditions. In both cases the ions entered the collision cell having initial thermal internal energy distributions corresponding to $T_{\mathrm{INT}}=600 \mathrm{~K}$; these distributions evolved as a result of ions colliding with argon atoms. The conditions at the pressure of $0.027 \mathrm{~Pa}$ (0.2 mTorr) correspond to parent ions, on average, experiencing less than one collision per trajectory. Here, most of the parent ions pass the hexapole cell without collisions and only a fraction of them collides with argon. As can be seen from the plot, the resultant energy distribution is very close to the original energy distribution of the ions entering the collision cell, i.e., the Boltzmann distribution at $600 \mathrm{~K}$. It is somewhat shifted relative to the Boltzmann curve towards higher energies and can still be represented by a thermal distribution function corresponding to a higher effective internal temperature $\left(T_{\text {INT }}=635 \mathrm{~K}\right)$. The $0.53 \mathrm{~Pa}(4$ mTorr) conditions correspond to multiple collisions per trajectory. The difference with the single-collision case is quite visible: the population is shifted towards higher energies. The energy distribution does not resemble a Boltzmann curve, which is emphasized in Figure 6 by presenting a thermal distribution curve corresponding to $T_{\text {INT }}=970 \mathrm{~K}$ on the same plot. To some extent, the distribution resembles a lower-temperature Boltzmann curve shifted along the energy axis (the dashed line in Figure 6c), however, the similarity is not exact. The $\mathrm{E}_{\mathrm{ACT}}$ distribution in Figure $6 \mathrm{c}$ includes a fraction of the parent ions with $E_{\mathrm{ACT}}<\Delta \mathrm{H}_{0}^{0}(1)$ that, nevertheless, contribute to dissociation because of the contribution from the energy of adiabatic rotation $\left(E_{2 \mathrm{D}}\right)$, which allows overcoming the centrifugal barrier to decomposition.

\section{General Discussion of the Method and the Results}

The current work presents the most detailed modeling study of collisional excitation and dissociation of ions in a tandem mass spectrometer, in the sense that several processes influencing the experimentally measured quantities are modeled using basic physical principles. These processes include parent ion flight in the rf electromagnetic field of the hexapole collision cell, vibrational and rotational energy-transfer, scattering of parent ions due to collisions with the monoatomic collider gas, reactions of decomposition of the energized parent ions, product ion flight in the hexapole electromagnetic field, and scattering of product ions due to collisions. The level of detail in the modeling of individual processes contributing to the overall phenomenon distinguishes the current work from earlier studies, where generally one or two of important processes are modeled in depth and other contributing factors are assumed to either be unimportant or contribute in an "averaged" way. Explicit accounting for a multitude of physical processes enables distinguishing between important and unimportant factors and identification of those that require more detailed and accurate modeling.

Importance of some of these factors and associated quantities, such as reaction energy barrier or the degree 
of initial vibrational excitation of ions before entering the collision cell, is fairly obvious. At the same time, significance of another contributing factor, scattering of product ions from the hexapole collision cell, was not a priori apparent. It was observed that the loss of product ions can exceed that of the parent ions, thus significantly affecting the values of fragmentation efficiency. Therefore, quantitative modeling of ion CID in apparatuses where ion scattering is not negligible needs to include accounting for both parent and product ion scattering. Moreover, comparison between experimental ion fragmentation mass spectra obtained using different instrument types or even different implementations of the same type of mass spectrometer may be affected by different degrees of scattering and ion loss.

A number of model parameters had to be adjusted in the process of modeling to achieve agreement with experiment. Even though the values of all adjustable parameters are within reasonable limits, variations in these parameters can drastically change modeling results. The results demonstrate that the approach developed in this study is generally capable of quantitatively reproducing experimental data on ion dissociation in CID MS experiments. In this respect, they provide support for using quasiclassical trajectories for modeling energy transfer in ion-atom collisions. However, given the flexibility of the model parameters, the degree of accuracy of the per-collision activation function cannot be ascertained. In this respect, the relative success of the model when applied to dissociation of tert-butyl benzylammonium, which has the reaction enthalpy lower than that of reaction 1 by $28 \mathrm{~kJ} \mathrm{~mol}^{-1}$, is promising. More attempts to compare experiment and theory are needed, using ion decomposition reactions with wide differences in reaction energy barriers. Another concern is the adequacy of the quasiclassical trajectory description of scattering in ion-atom collisions. As discussed above, scattering of parent and product ions is important, and imperfect description of collisions can result in deficient accounting for ion scattering. Furthermore, potential effects of other parameters, such as, e.g., shape of the initial internal energy distribution of ions, fringe field effects, and tuning parameters of the second quadrupole filter have not been studied. It is highly desirable to design experiments where potential effects of these parameters are controlled or, ideally, separated from the effects of collisional energy and structure of the ions undergoing the reaction.

The computational models of both reactions 1 and 2 were created within the framework of the RRKM method, which is based on the assumption of quick randomization of energy in the active degrees of freedom of the molecule undergoing reaction. Potential non-RRKM effects, such as those reported in references [82] and [83], are not included in these models. In principle, use of quasiclassical trajectory calculations enables accounting for such effects (e.g., refs [47, 84, 85]. However, such accounting for non-statistical effects requires more extensive exploration of the reaction potential energy surface than that used in the current work.

Practical CID studies of polyatomic ions are generally performed under the conditions corresponding to multiple collisions between the ions and the collider gas, at pressures close to those used at the highpressure end of the range of the current study. In many practical studies, conditions are selected to result in a certain fixed value of the ion dissociation efficiency. It is thus useful to examine the performance of the models of reactions 1 and 2 at the pressures of $0.27-0.53 \mathrm{~Pa}$ (2.0-4.0 mTorr) and fixed ion dissociation percentages. Since the models reasonably predict the energies $\left(E_{\mathrm{KIN}}\right)$ of the onset of ion dissociation, the low and intermediate dissociation percentage ( $\sim 5 \%$ and $\sim 50 \%$ ) conditions are described adequately, with the corresponding values of $E_{\mathrm{KIN}}$ being in general agreement with the experimental values within $\sim 1 \mathrm{eV}$. At the same time, conditions corresponding to large dissociation percentages, e.g., $90 \%$, are described with varying degrees of success. The agreement is generally good under the conditions where saturation in ion fragmentation efficiency is observed at high $E_{\mathrm{KIN}}$ values; however, a pronounced disagreement is visible for reaction 1 at $0.27 \mathrm{~Pa}(2.0$ mTorr), where the calculated fragmentation efficiency does not reach the value of $90 \%$ while the experimental one does (Figure 1b).

\section{Conclusions}

Collision-induced dissociation of two small polyatomic ions (benzylammonium and 4-tert-butyl benzylammonium) was studied experimentally by electrospray ionization mass spectrometry. The instrument used was a tandem quadrupole-hexapole-quadrupole CID mass spectrometer. The dependences of ion fragmentation efficiency on the kinetic energy of ions entering the hexapole collision cell were determined at several fixed values of the collider gas (argon) pressure. The results obtained for $\mathrm{C}_{6} \mathrm{H}_{5} \mathrm{CH}_{2} \mathrm{NH}_{3}^{+}$(reaction 1) were used to develop a theoretical model of ion collisional excitation, scattering, and decomposition, to evaluate the model performance, and to adjust its critical parameters. The results obtained for $\mathrm{C}\left(\mathrm{CH}_{3}\right)_{3} \mathrm{C}_{6} \mathrm{H}_{4} \mathrm{CH}_{2} \mathrm{NH}_{3}^{+}$decomposition (reaction 2) were used for evaluation of agreement with experiment only, with only one model parameter adjusted.

The theoretical Monte Carlo model of ion collisional excitation, scattering, and decomposition was based on first-principles simulation of individual ion's flight through the hexapole collision cell, its collisions with the atoms of the collider gas, the resultant vibrational and rotational excitation and scattering, and decomposition into ammonia and the corresponding product ion. The trajectories of ion flight through the collision cell were modeled by integrating classical equations of motion of a charged point mass in rf electromagnetic field. Collisional activation was described by performing quasiclassical trajectory calculations for the ion - 
atom encounters. Kinetics of ion dissociation was modeled using the RRKM method.

The results of modeling demonstrate sensitivity to scattering of product ions from the hexapole collision cell; loss of product ions due to this scattering can significantly exceed, in relative terms, that of the parent ions. Failure to account for product ion loss results in incorrect values of fragmentation efficiency and qualitatively incorrect shapes of the ion fragmentation efficiency versus kinetic energy curves. Modeling results are also moderately sensitive to the distribution of initial ion velocities orthogonal to the axis of the collision cell; using a thermal distribution with the characteristic temperature of $600 \mathrm{~K}$ resulted in agreement with experiment.

Dissociation of $t$-butyl benzylammonium ion (reaction 2) was modeled using the same model parameters that were used in calculations for reaction 1, with only one model parameter, the effective initial internal temperature of the ions, adjusted. Reaction 2 has an energy barrier that is smaller than that of reaction 1 by $28 \mathrm{~kJ}$ $\mathrm{mol}^{-1}$; the number of active degrees of freedom of $t$-butyl benzylammonium (85) is larger than that of unsubstituted benzylammonium (49). Despite the differences, the results of simulations are in general agreement with the experimental data. The agreement provides support for the theoretical approach developed in the current work and for its potential use for predicting fragmentation efficiencies in other similar reactions.

Analysis of energy distribution functions obtained in modeling demonstrates that these functions strongly depend on the numbers of collisions between the ion and the atoms of the collider gas (single versus multiple collisions) and, in general, have non-Boltzmann shapes.

\section{Acknowledgments}

The authors express their thanks to Dr. K. F. Lim and Dr. W. L. Hase for providing them with the copies of quasiclassical trajectory modeling programs (MARINER and VENUS).

\section{Appendix A Supplementary Material}

Supplementary material associated with this article may be found in the online version at doi:10.1016/ j.jasms.2009.11.007.

\section{References}

1. Chapman, J. R. Ed. Mass Spectrometry of Protein and Peptides; Humana Press: Totowa, NJ, 2000

2. Glish, G. L.; Vachet, R. W. The basics of mass spectrometry in the twenty-first century. Nat. Rev. Drug Dic. 2003, 2, 140-150.

3. Lin, D.; Tabb, D. L.; Yates, J. R. I. Large-Scale Protein Identification Using Mass Spectrometry. Biochim. Biophys. Acta 2003, 1646, 1-10.

4. Aebersold, R. A Mass Spectrometric Journey into Protein and Proteome Research. J. Am. Soc. Mass Spectrom. 2003, 14, 685-695.

5. McLuckey, S. A.; Wells, J. M. Mass Analysis at the Advent of the 21st Century. Chem. Rev. 2001, 101, 571-606.

6. Shukla, A. K.; Futrell, J. H. Tandem Mass Spectrometry: Dissociation of Ions by Collisional Activation. J. Mass Spectrom. 2000, 35, 1069-1090.

7. McLuckey, S. A. Principles of Collisional Activation in Analytical Mass Spectrometry. J. Am. Soc. Mass Spectrom. 1992, 3, 559-614.
8. McLuckey, S. A.; Goeringer, D. E. Slow Heating Methods in Tandem Mass Spectrometry. J. Mass Spectrom. 1997, 32, 461-474.

9. Paizs, B.; Suhai, S. Fragmentation Pathways of Protonated Peptides. Mass Spectrom. Rev. 2005, 24, 508-548.

10. Armentrout, P. B. Mass Spectrometry-Not Just a Structural Tool: The Use of Guided Ion Beam Tandem Mass Spectrometry to Determine Thermochemistry. J. Am. Soc. Mass Spectrom. 2002, 13, 419-434.

11. Armentrout, P. B. Statistical Modeling of Sequential Collision-Induced Dissociation Thresholds. J. Chem. Phys. 2007, 126, 234-302.

12. Biemann, K. Contributions of Mass Spectrometry to Peptide and Protein Structure. Biomed. Environ. Mass Spectrom. 1984, 16, 99-111.

13. Harrison, A. G.; Csizmadia, I. G.; Tang, T.-H.; Tu, Y.-P. Reaction Competition in the Fragmentation of Protonated Dipeptides. J. Mass Spectrom. 2000, 35, 683-688.

14. Roepstorff, P.; Fohlman, J. Proposal for a Common Nomenclature for Sequence Ions in Mass-Spectra of Peptides. Biomed. Mass Spectrom. 1984, 11, 601-601.

15. Tabb, D. L.; Smith, L. L.; Breci, L. A.; Wysocki, V. H.; Lin, D.; Yates, J. R. Statistical Characterization of Ion Trap Tandem Mass Spectra from Doubly Charged Tryptic Peptides. Anal. Chem. 2003, 75, 1155-1163.

16. Wysocki, V. H.; Tsaprailis, G.; Smith, L. L.; Breci, L. A. Mobile and Localized Protons: A Framework for Understanding Peptide Dissociation. J. Mass Spectrom. 2000, 35, 1399-1406.

17. Polce, M. J.; Ren, D.; Wesdemiotis, C. Dissociation of the Peptide Bond in Protonated Peptides. J. Mass Spectrom. 2000, 35, 1391-1398.

18. Laskin, J.; Futrell, J. H. Collisional Activation of Peptide Ions in FT-ICR Mass Spectrometry. Mass Spectrom. Rev. 2003, 22, 158-181.

19. Laskin, J.; Byrd, M.; Futrell, J. Internal Energy Distributions Resulting from Sustained Off-Resonance Excitation in FTMS. I. Fragmentation of the Bromobenzene Radical Cation. Int. J. Mass Spectrom. 2000, 195, 285-302.

20. Muntean, F.; Armentrout, P. B. Guided Ion Beam Study of CollisionInduced Dissociation Dynamics: Integral and Differential Cross Sections. J. Chem. Phys. 2001, 115, 1213-1228.

21. Meroueh, O.; Hase, W. L. Collisional Activation of Small Peptides. J. Phys. Chem. A 1999, 103, 3981-3990.

22. Meroueh, O.; Hase, W. L. Energy Transfer Pathways in the Collisional Activation of Peptides. Int. J. Mass Spectrom. 2000, 201, 233-244.

23. Marzluff, E. M.; Campbell, S.; Rodgers, M. T.; Beauchamp, J. L. Collisional Activation of Large Molecules is an Efficient Process. J. Am. Chem. Soc. 1994, 116, 6947-6948.

24. Marzluff, E. M.; Campbell, S.; Rodgers, M. T.; Beauchamp, J. L. Low-Energy Dissociation Pathways of Small Deprotonated Peptides in the Gas Phase. J. Am. Chem. Soc. 1994, 116, 7787-7796.

25. Alexander, A. J.; Boyd, R. K. Experimental Investigations of Factors Controlling the Collision-Induced Dissociation Spectra of Peptide Ions in a Tandem Hybrid Mass Spectrometer. 1. Leucine Enkephalin. Int. J. Mass Spectrom. Ion Processes 1989, 90, 211-240.

26. Alexander, A. J.; Thibault P.; Boyd, R. K. Target Gas Excitation in Collision-Induced Dissociation-a Reinvestigation of Energy Loss in Collisional Activation of Molecular Ions of Chlorophyll- $\alpha$. J. Am. Chem. Soc. 1990, 112, 2484-2491.

27. Thibault P.; Alexander, A. J.; Boyd, R. K. High-Energy Collisional Activation Studied Via Angle-Resolved Translational Energy Spectra of Survivor Ions. J. Am. Soc. Mass Spectrom. 1993, 4, 835-844.

28. Thibault, P.; Alexander, A. J.; Boyd, R. K.; Tomer. K. B. Delayed Dissociation Spectra of Survivor Ions from High-Energy Collisional Activation. J. Am. Soc. Mass Spectrom. 1993, 4, 845-854.

29. Chen, G.; Cooks, R. G.; Bunk, D. M.; Welch, M. J.; Christie, J. R Partitioning of Kinetic Energy to Internal Energy in the Low Energy Collision-Induced Dissociation of Proton-Bound Dimers of Polypeptides. Int. J. Mass Spectrom. 1999, 185/186/187, 75-90.

30. Heeren, R. M. A.; Vekey, K. A Novel Method to Determine Collisional Energy Transfer Efficiency by Fourier Transform Ion Cyclotron Resonance Mass Spectrometry. Rapid Commun. Mass Spectrom. 1998, 12, 1175-1181.

31. Collette, C.; De Pauw, E. Calibration of the Internal Energy Distribution of Ions Produced by Electrospray. Rapid Commun. Mass Spectrom. 1998, 12, 165-170.

32. Collette, C.; Drahos, L.; De Pauw, E.; Vekey, K. Comparison of the Internal Energy Distributions of Ions Produced by Different Electrospray Sources. Rapid Commun. Mass Spectrom. 1998, 12, 1673-1678.

33. Drahos, L.; Heeren, R. M. A.; Collette, C.; De Pauw, E.; Vekey, K. Thermal Energy Distribution Observed in Electrospray Ionization. J. Mass Spectrom. 1999, 34, 1373-1379.

34. Drahos, L.; Sztaray, J.; Vekey, K. Theoretical Calculation of Isotope Effects, Kinetic Energy Release, and Effective Temperatures for Slkylamines. Int. J. Mass Spectrom. 2003, 225, 233-248.

35. Drahos, L.; Vekey, K. Mass Kinetics: A Theoretical Model of Mass Spectra Incorporating Physical Processes, Reaction Kinetics, and Mathematical dDescription. J. Mass Spectrom. 2001, 36, 237-263.

36. Naban-Maillet, J.; Lesage, D.; Bossee, A.; Gimbert, Y.; Sztaray, J.; Vekey, K.; Tabet, J. C. Internal Energy Distribution in Electrospray Ionization. J. Mass Spectrom. 2005, 40, 1-8.

37. Pak, A.; Lesage, D.; Gimbert, Y.; Vekey, K.; Tabet, J. C. Internal Energy Distribution of Peptides in Electrospray Ionization: ESI and CollisionInduced Dissociation Spectra Calculation. J. Mass Spectrom. 2008, 43, 447-455. 
38. Laskin, J.; Denisov, E.; Futrell, J. H. A Comparative Study of CollisionInduced and Surface-Induced Dissociation. 1. Fragmentation of Protonated Dialanine. I. Am. Chem. Soc. 2000, 122, 9703-9714.

39. Laskin, J.; Denisov, E.; Futrell, J. H. Comparative Study of CollisionInduced and Surface-Induced Dissociation. 2. Fragmentation of Small Alanine-Containing Peptides in FT-ICR MS. J. Phys. Chem. B 2001, 105, 1895-1900.

40. Laskin, J.; Denisov, E.; Futrell, J. H. Fragmentation Energetics of Small Peptides from Multiple-Collision Activation and Surface-Induced Dissociation in FT-ICR MS. Int. J. Mass Spectrom. 2002, 219, 189-201.

41. Laskin, J.; Futrell, J. H. Internal Energy Distributions Resulting from Sustained Off-Resonance Excitation in Fourier Transform Ion Cyclotron Resonance Mass Spectrometry. II. Fragmentation of the 1-Bromonaphthalene Radical Cation. J. Phys. Chem. A 2000, 104, 5484-5494.

42. Laskin, J.; Futrell, J. H. On the Efficiency of Energy Transfer in Collisional Activation of Small Peptides. J. Chem. Phys. 2002, 116, 4302-4310.

43. Muntean, F.; Armentrout, P. B. Modeling Kinetic Shifts and Competition in Threshold Collision-Induced Dissociation. Case study: nButylbenzene Cation Dissociation. J. Phys. Chem. A 2003, 107, 74137422.

44. Armentrout, P. B. Threshold Collision-Induced Dissociations for the Determination of Accurate Gas-Phase Binding Energies and Reaction Barriers. Modern Mass Spectrom. 2003, 225, 233-262.

45. Khan, F. A. C. D. E.; Schultz, R. H.; Armentrout, P. B. Sequential Bond-Energies of $\mathrm{Cr}(\mathrm{CO})_{\times}^{+}, \mathrm{x}=1-6$. J. Phys. Chem. 1993, 97, 7978-7987.

46. Rodgers, M. T.; Ervin, K. M.; Armentrout, P. B. Statistical Modeling of Collision-Induced Dissociation Thresholds. J. Chem. Phys. 1997, 106 , 4499-4508.

47. Martinez-Nunez, E.; Fernandez-Ramos, A.; Vasquez, S. A.; Marques, J.; Xue, M.; Hase, W. L. Quasiclassical Dynamics Simulation of the Collision-Induced dissociation $\mathrm{Cr}(\mathrm{CO})_{6}^{+}$with Xe. J. Chem. Phys. 2006, 123, 154311.

48. Certain commercial instruments and materials are identified in this article to adequately specify the procedures. In no case does such identification imply recommendation or endorsement by NIST, nor does it imply that the instruments or materials are necessarily the best available for this purpose.

49. Becke, A. D. A New Mixing of Hartree-Fock and Local DensityFunctional Theories. J. Chem. Phys. 1993, 98, 1372-1377.

50. Lee, C. T.; Yang, W. T.; Parr, R. G. Development of the Colle-Salvetti Correlation-Energy Formula into a Functional of the Electron Density. Phys. Rev. B 1988, 37, 785-789.

51. Cizek, J. Use of the Cluster Expansion and the Technique of Diagrams in Calculations of Correlation Effects in Atoms and Molecules. Adv. Chem. Phys. 1969, 14, 35-89.

52. Bartlett, R. J.; Purvis, G. D. Many-Body Perturbation-Theory, CoupledPair Many-Electron Theory, and Importance of Quadruple Excitations for Correlation Problem. Int. J. Quant. Chem. 1978, 14, 516-581.

53. Purvis, G. D. I.; Bartlett, R. J. A Full Coupled-Cluster Singles and Doubles Model: The Inclusion of Disconnected Triples. J. Chem. Phys. 1982, 76, 1910-1918.

54. Kendall, R. A.; Dunning, T. H. Jr.; Harrison, R. J. Electron Affinities of the First-Row Atoms Revisited. Systematic Basis Sets and Wave Functions. J. Chem. Phys. 1992, 96, 6796-6806.

55. Frisch, M. J.; Trucks, G. W.; Schlegel, H. B.; Scuseria, G. E.; Robb, M. A.; Cheeseman, J. R.; Montoomery, J. A. Jr.; Vreven, T.; Kudin, K. N. Burant, J. C.; Millam, J. M.; Iyengar, S. S.; Tomasi, J.; Barone, V.; Mennucci, B.; Cossi, M.; Scalmani, G.; Rega, N.; Petersson, G. A.; Nakatsuji, H.; Hada, M.; Ehara, M.; Toyota, K.; Fukuda, R.; Hasegawa, J.; Ishida, M.; Nakajima, T.; Honda, Y.; Kitao, O.; Nakai, H.; Klene, M.; Li, X.; Knox, J. E.; Hratchian, H. P.; Cross, J. B.; Bakken, V.; Adamo, C.; Jaramillo, J.; Gomperts, R.; Stratmann, R. E.; Yazyev, O.; Austin, A. J.; Cammi, R.; Pomelli, C.; Ochterski, J. W.; Ayala, P. Y.; Morokuma, K.; Voth, G. A.; Salvador, P.; Dannenberg, J. J.; Zakrzewski, V. G.; Dapprich, S.; Daniels, A. D.; Strain, M. C.; Farkas, O.; Malick, D. K.; Rabuck, A. D.; Raghavachari, K.; Foresman, J. B.; Ortiz, J. V.; Cui, Q.; Baboul A. G.; Clifford, S.; Cioslowski, J.; Stefanov, B. B.; Liu, G.; Liashenko, A.; Piskorz, P.; Komaromi, I.; Martin, R. L.; Fox, D. J.; Keith, T.; Al-Laham, M. A.; Peng, C. Y.; Nanayakkara, A.; Challacombe, M.; Gill, P. M. W.; Johnson, B.; Chen, W.; Wong, M. W.; Gonzalez, C.; Pople, J. A. Gaussian 03, Revision C 02; Gaussian, Inc.: Wallingford, CT, 2004

56. Durant, J. L. Evaluation of Transition State Properties by Density Functional Theory. Chem. Phys. Lett. 1996, 256, 595-602.

57. Duncan, W. T.; Truong, T. N. Thermal and Vibrational-State Selected Rates of the $\mathrm{CH}_{4}+\mathrm{Cl} \rightarrow \mathrm{HCl}+\mathrm{CH}_{3}$ Reaction. J. Chem. Phys. 1995, 103, 9642-9652.

58. Maity, D. K.; Duncan, W. T.; Truong, T. N. Direct Ab Initio Dynamics Studies of the Hydrogen Abstraction Reactions of Hydrogen Atom with Fluoromethanes. J. Phys. Chem. A 1999, 103, 2152-2159.
59. Truong, T. N. A Direct Ab-Initio Dynamics Approach for Calculating Thermal Rate Constants Using Variational Transition-State Theory and Multidimensional Semiclassical Tunneling Methods-an Application to the $\mathrm{CH}_{4}+\mathrm{H} \rightarrow \mathrm{CH}_{3}+\mathrm{H}_{2}$ Reaction. J. Chem. Phys. 1994, 100, 8014-8025.

60. Truong, T. N.; Duncan, W. T.; Bell, R. L. Direct Ab Initio Dynamics Methods for Calculating Thermal Rates of Polyatomic Reactions. In Chemical Applications of Density Functional Theory; Laird, B. B.; Ross, R. B.; Ziegler, T., Eds.; American Chemical Society: Washington, DC, 1996; pp 85-104.

61. Mora-Diez, N.; Boyd, R. J. A Computational Study of the Kinetics of the $\mathrm{NO}_{3}$ Hydrogen-Abstraction Reaction from a Series of Aldehydes (XCHO: $\mathrm{X}=\mathrm{F}, \mathrm{Cl}, \mathrm{H}, \mathrm{CH}_{3}$ ). J. Phys. Chem. A 2002, 106, 384-394.

62. Knyazev, V. D. Reactivity Extrapolation from Small to Large Molecular Systems Via Isodesmic Reactions for Transition States (RESLIR). J. Phys. Chem. 2004, 108, 10714-10722.

63. Benson, S. W. Thermochemical Kinetics, 2nd Ed.; John Wiley and Sons: New York, 1976.

64. Robinson, P. J.; Holbrook, K. A. Unimolecular Reactions; WileyInterScience: New York, 1972.

65. Gilbert, R. G.; Smith, S. C. Theory of Unimolecular and Recombination Reactions; Blackwell: Oxford, 1990.

66. Holbrook, K. A.; Pilling, M. J.; Robertson, S. H. Unimolecular Reactions; 2nd ed. Wiley: New York, 1996.

67. Chase, M. W. Jr. NIST-JANAF Thermochemical Tables, 4th Edition. Monograph. J. Phys. Chem. Ref. Data 1998, 9, 1-1951.

68. Carson, A. S.; Laye, P. G.; Yrekli, M. The Enthalpy of Formation of Benzylamine. J. Chem. Thermodyn. 1977, 9, 827-829.

69. Tsang, W. Heats of Formation of Organic Free Radicals by Kinetic Methods. In Energetics of Organic Free Radicals; Martinho Simoes, J. A.; Greenberg, A.; Liebman, J. F., Eds.; Blackie Academic and Professional: London, 1996; pp 22-58.

70. Lias,, S. G. Ionization Energy Evaluation for Benzyl Radical. Web Page, http://webbook.nist.gov, accessed Sept. 2, 2008

71. Hunter, E. P.; Lias, S. G. Evaluated Gas Phase Basicities and Proton Affinities of Molecules: An Update. J. Phys. Chem. Ref. Data 1998, 27, 413-656.

72. Colclough, A. R. Two Theories of Experimental Error. J. Res. Nat. Bur. Stand. 1987, 92, 167-185.

73. Baer, T.; Hase, W. L. Unimolecular Reaction Dynamics; Oxford University Press: New York, 1996; pp 324-368.

74. Lim, K. F., Hase, W. L. MARINER: A General Monte Carlo Classical Trajectory Program. http://www.deakin.edu.au/ $\lim /, 1990$.

75. Hase, W. L.; Duchovic, R. J.; Hu, X.; Komornicki, A.; Lim, K. F.; Lu, D.-H.; Peslherbe, G. H.; Swamy, K. N.; Vande Linde, S. R.; Varandas, A.; Wang, H.; Wolf, R. J. VENUS96: A General Chemical Dynamics Computer Program. Quantum Chem. Program Exchange Bull. 1996, 16, 43.

76. Cornell, W. D.; Cieplak, P.; Bayly, C. I.; Gould, I. R.; Merz, K. M. Ferguson, D. M.; Spellmeyer, D. C.; Fox, T.; Caldwell, J. W.; Kollman, P. A. A Second Generation Force-Field for the Simulation of Proteins, Nucleic-Acids, and Organic Molecules. J. Am. Chem. Soc. 1995, 117, 5179-5197.

77. Jorgensen, W. L.; Maxwell, D. S.; Tirado-Rives, J. Development and Testing of the OPLS All-Atom Force Field on Conformational Energetics and Properties of Organic Liquids. J. Am. Chem. Soc. 1996, 118, 1122511236.

78. Price, M. L. P.; Ostrovsky, D.; Jorgensen, W. L. Gas-Phase and LiquidState Properties of Esters, Nitriles, and Nitro Compounds with the OPLS-AA Force Field. J. Comput. Chem. 2001, 22, 1340-1352.

79. Pople, J. A.; Head-Gordon, M.; Raghavachari, K. Quadratic Configuration Interaction. A General Technique for Determining Electron Correlation Energies. J. Chem. Phys. 1987, 87, 5968-5975.

80. Friedman, M. H.; Yergey, A. L.; Campana, J. E. Fundamentals of Ion Motion in Electric Radio-Frequency Multipole Fields. J. Phys. E: Sci. Instrum. 1982, 15, 53-61.

81. Scientific Instrument Services, I. SIMION, Simulation Software for Modeling of Electron and Ion Optics; Ringoes, NI, 2004.

82. Fenn, P. T.; Chen, Y. J.; Stimson, S.; Ng, C. Y. Dissociation of $\mathrm{CH}_{3} \mathrm{SH}^{+}$ by Collisional Activation: Evidence of Nonstatistical Behavior. J. Phys. Chem. A 1997, 101, 6513-6522.

83. Chen, Y. J.; Fenn, P. T.; Lau, K. C.; Ng, C. Y.; Law, C. K.; Li, W. K. Study of the dissociation of $\mathrm{CH}_{3} \mathrm{SCH}_{3}^{+}$by Collisional Activation: Evidence of Nonstatistical Behavior. J. Phys. Chem. A 202, 106, 9729-9736.

84. Martinez-Nunez, E.; Vazquez, S. A. Dynamics of Unimolecular Reactions in Gas Phase Deviations from Statistical Behavior. Quimica Nova 2002, 25, 579-588.

85. Martínez-Núñez, E.; Vázquez, S. A.; Aoiz, F. J.; Castillo, J. F. Quasiclassical Trajectory Study of the Collision-Induced Dissociation Dynamics of $\mathrm{Ar}+\mathrm{CH}_{3} \mathrm{SH}^{+}$Using an $\mathrm{Ab}$ Initio Interpolated Potential Energy Surface. J. Phys. Chem. A 2006, 110, 1225-1231. 